Policy Research Working Paper 5071

\title{
Pricing Externalities from Passenger Transportation in Mexico City
}

\author{
Ian W.H. Parry \\ Govinda R. Timilsina
}

The World Bank

Development Research Group

Environment and Energy Team

September 2009 
Policy Research Working Paper 5071

\begin{abstract}
The Mexico City Metropolitan Area has been suffering severely from transportation externalities such as accidents, air pollution, and traffic congestion. This study examines pricing instruments to reduce these externalities using an analytical and numerical model. The study shows that the optimal levels of a gasoline tax and a congestion toll on automobiles could generate social benefits, measured in terms of welfare gain, of US $\$ 132$ and US\$109 per capita, respectively, through the reduction of externalities. The largest component of the welfare gains comes from reduced congestion, followed by local air pollution reduction. The optimal toll and tax would, however, double the cost of driving and could be
\end{abstract}

politically sensitive. Still, more than half of those welfare gains could be obtained through a more modest tax or toll, equivalent to $\$ 1$ per gallon of gasoline. The welfare gains from reforming the pricing of public transportation are small relative to those from reforming the taxation of automobiles. Although the choice among travel modes depends on specific circumstances, in the absence of road travel pricing that accounts for externalities, there will be potential for higher investment in roads relative to mass transit. Given the rapidly increasing demand for transportation infrastructure in Mexico City, careful efforts should be made to include the full social costs of travel in evaluating alternative infrastructure investments.

This paper-a product of the Environment and Energy Team, Development Research Group—is part of a larger effort in the department to study climate change and clean energy issues. Policy Research Working Papers are also posted on the Web at http://econ.worldbank.org. The author may be contacted at gtimilsina@worldbank.org.

The Policy Research Working Paper Series disseminates the findings of work in progress to encourage the exchange of ideas about development issues. An objective of the series is to get the findings out quickly, even if the presentations are less than fully polished. The papers carry the names of the authors and should be cited accordingly. The findings, interpretations, and conclusions expressed in this paper are entirely those of the authors. They do not necessarily represent the views of the International Bank for Reconstruction and Development/World Bank and its affliated organizations, or those of the Executive Directors of the World Bank or the governments they represent. 


\title{
Pricing Externalities from Passenger Transportation in Mexico City
}

\author{
Ian W.H. Parry \\ Resources for the Future
}

Govinda R. Timilsina*

The World Bank

Key words: Optimal travel pricing; congestion and emission control; transport sector externalities; welfare gains; Mexico City.

\footnotetext{
*Corresponding author. The World Bank, 1818 H Street, NW, Washington DC, 20433. Phone (202) 473-2767; Email gtimilsina@worldbank.org. We sincerely thank Gustavo Saltiel, Kenneth Small, Lucas Davis, Gershon Feder, Mike Toman and two anonymous referees for their valuable comments and Hari Dulal for his research assistance. The views expressed in this paper are those of the authors only, and do not necessarily represent the World Bank and its affiliated organizations.
} 


\section{Introduction}

The Mexico City Metropolitan Area (MCMA) is ranked among the most polluted cities in the world and is also one of the most congested in terms of lowest average speed of passenger vehicles (Table 1). Air pollution is currently responsible for 4,000 premature deaths a year (INE, 2003) and according to our calculations below, the annual costs of traffic delays are $\$ 580$ per capita. Moreover, pressure on pollution and congestion will continue as the population of the metropolitan area is projected to increase from around 19 million today to 26 million by 2020 (Molina and Molina 2002).

Since 1990, a number of policies have been introduced with the aim of partly alleviating Mexico City's air quality and congestion problems (Sánchez 2000, Vergara and Haeussling 2007). Many environmental measures are targeted at the transportation sector which, according to O'Ryan and Larraguibel (2000), accounts for around 40 percent of particulate emissions and 75 percent of nitrogen dioxide emissions (a precursor for ozone), the two most serious pollutants from a local public health perspective. These measures include mandates for three-way catalytic converters, progressively more stringent emissions per mile standards for new cars, periodic emissions inspections for in-use vehicles, and the phase out of leaded gasoline. ${ }^{1}$ Policies to alleviate congestion include the "Today Don't Drive" program, which bans most drivers from using their vehicles one weekday per week (Davis, 2008). In addition, mass transit has been upgraded in several respects, for example by opening a rapid bus system on the main north-south arterial route in 2005 and by introducing high-speed suburban rail links.

These policies have met with mixed success. Although the trend of rising air pollution during the 1980s and 1990s has been reversed, particulate matter and ozone levels remain well above Mexican air quality standards, in part because growing demand for energy counteracts reductions in energy intensity (Molina and Molina 2002, Ch. 2, Bell et al. 2006). And people can evade the no-drive day program by using second vehicles (Eskeland 1992; Eskeland and Tarhan,1995).

An alternative (and in some respects complementary) strategy for mitigating pollution, congestion, and also traffic accidents, and that has not been tried in Mexico City, is reforming the system of transportation prices. One option would be to raise the (state-controlled) price of

\footnotetext{
${ }^{1}$ For discussion and analysis of other pollution initiatives see INE (2003), Molina and Molina (2002), and West et al. (2003).
} 
gasoline, which fuels passenger cars and (privately operated) microbuses. Another option is to introduce some form of tolling by the mile for passenger cars though, as discussed below, implementing this would require overcoming significant challenges. Whether microbuses should be taxed or subsidized on a per mile basis is not immediately clear even in principle; while they deter private use of automobiles, they themselves contribute to congestion and pollution. A further possibility is to adjust fares charged to users of the public bus and subway system.

Table 1. Ranking of Selected Megacities Based on Ambient Air Quality and Road Travel Speed

\begin{tabular}{|c|c|c|c|c|c|}
\hline Megacities in 2000 & $\begin{array}{c}\text { Total suspended } \\
\text { particulates }\left(\mu \mathrm{g} \mathrm{m}^{-3}\right) \\
{[\text { Rank] }}\end{array}$ & $\begin{array}{l}\text { Sulfur dioxide } \\
\qquad\left(\mu \mathrm{g} \mathrm{m}^{-3}\right) \\
{[\text { Rank }]}\end{array}$ & $\begin{array}{c}\text { Nitrogen dioxide } \\
\left(\mu \mathrm{g} \mathrm{m}^{-3}\right) \\
{[\text { Rank }]} \\
\end{array}$ & $\begin{array}{c}\text { Multi-pollutant } \\
\text { index } \\
\text { [Rank] } \\
\end{array}$ & $\begin{array}{c}\text { Average road speed } \\
\text { miles per hour } \\
\text { [Rank] }\end{array}$ \\
\hline Tokyo & $40[15]$ & $19[9]$ & $55[11]$ & $-0.27[16]$ & $16.2[9]$ \\
\hline Mexico City & $201[10]$ & $47[4]$ & $56[10]$ & $0.52[10]$ & $14.0[6]$ \\
\hline New York - Newark & $27[18]$ & $22[7]$ & $63[7]$ & $-0.23[14]$ & $23.9[14]$ \\
\hline São Paulo & $53[14]$ & $18[10]$ & $47[12]$ & $-0.29[17]$ & $15.0[8]$ \\
\hline Mumbai (Bombay) & $243[9]$ & $19[9]$ & $43[14]$ & $0.39[11]$ & $13.8[5]$ \\
\hline Kolkata (Calcutta) & $312[6]$ & $19[9]$ & $37[15]$ & $0.59[9]$ & na \\
\hline Shanghai & $246[8]$ & $53[3]$ & $73[5]$ & $0.87[8]$ & $12.4[4]$ \\
\hline Buenos Aires & $185[11]$ & $20[8]$ & $20[18]$ & $-0.01[13]$ & $18.6[10]$ \\
\hline Delhi & $405[4]$ & $18[10]$ & $36[16]$ & $0.92[7]$ & $14.4[7]$ \\
\hline Los Angeles - Long Beach - Santa Ana & $39[16]$ & $9[13]$ & $66[6]$ & $-0.25[15]$ & $29.5[15]$ \\
\hline Osaka - Kobe & $34[17]$ & $19[9]$ & $45[13]$ & $-0.37[18]$ & $20.5[13]$ \\
\hline Jakarta & $271[7]$ & $35[6]$ & $120[3]$ & $1.24[5]$ & $11.6[2]$ \\
\hline Beijing & $377[5]$ & $90[2]$ & $122[2]$ & $2.01[2]$ & $11.1[1]$ \\
\hline Rio de Janeiro & $139[13]$ & $15[11]$ & $60[8]$ & $0.11[12]$ & $18.6[10]$ \\
\hline Cairo & $593[2]$ & $37[5]$ & $59[9]$ & $1.93[3]$ & $12.4[3]$ \\
\hline Dhaka & $516[3]$ & $120[1]$ & $83[4]$ & $2.40[1]$ & na \\
\hline Moscow & $150[12]$ & $15[11]$ & $170[1]$ & $1.07[6]$ & $18.6[10]$ \\
\hline Karachi & $668[1]$ & $13[12]$ & $30[17]$ & $1.81[4]$ & na \\
\hline
\end{tabular}

Notes

Pollution figures are for year 2000, while road speed is for 2005. $\mu \mathrm{g} \mathrm{m}-3$ is micrograms per cubic meter.

The multi pollutant index combines pollutants in the first three columns. Road speed is averaged across all passenger vehicles.

Sources: Gurjar et al. (2007) and MCD (2007).

In previous literature there is little in the way of a conceptual and empirical framework for assessing the benefits and costs of these pricing options for Mexico City. Such assessment in important for understanding which pricing reforms yield the biggest welfare gains, an important element for policymakers to gauge the extent to which transportation prices should be reformed. Other criteria, which are beyond our scope, would also be important to consider, including distributional impacts, political feasibility, ease of monitoring and enforcement of policy reforms. 
As regards prior related literature, a number of studies have examined the health impacts of pollution in Mexico City (e.g., Bell et al. 2006, Borja-Aburto et al. 1997, O'Neill et al. 2004, Molina and Molina 2002, Vergara and Haeussling 2007). However, these studies do not examine optimal pricing of multiple travel modes, and fuel, in the presence of multiple externalities. In the transportation literature, some network simulation models have been developed and used to quantify the optimal set of prices to deal with pollution and congestion externalities. For the most part, these have been applied to US or European cities (e.g., de Borger and Proost 2001, Safirova et al. 2008). They have not been calibrated and empirically applied specifically to Mexico City, or to other Latin American cities that might be broadly comparable, at least in a way that accounts for multiple externalities and fuel price-induced changes in vehicle fuel economy. Moreover, while containing less detail than a sophisticated computational network model, there is value in a conceptual analytical framework that provides explicit formulas for optimal policies and welfare gains from policy reform. This helps to clarify why some factors or parameters are important in policy evaluation, while others are not; it also makes transparent the implications of different assumptions where parameters are uncertain.

The aim of this paper is to develop, and apply to Mexico City, such an initial version of such an analytical framework, for roughly gauging the appropriate direction, and extent, of pricing reforms for passenger travel and fuel use. Our theoretical framework shares some, but not all, features of some previous analytical models used for optimally pricing gasoline and transit travel in the United States and Europe (Parry and Small 2005, 2008). In particular, the model is based on aggregate welfare maximization that does not allow treatment of efficiency or distributional issues associated with heterogeneous agents and imperfect markets. The formulas for optimal policies and welfare effects that are derived can be readily implemented in a spreadsheet, and easily updated with new information on parameter values. Thus, the analysis also is applicable to other, comparable urban centers in Latin America. While simplified, the model can provide some sense of the nature of optimal policies. In particular, the model captures key characteristics of its transportation system, such as the widespread use of microbuses, using region-specific parameters

Our analysis indicates that the optimal gasoline tax to reduce negative externalities from passenger transportation would be much higher (US\$ 2.72 per gallon) as compared to the prevailing excise tax of 17 cents per gallon. This corresponds to raising the retail gasoline price 
from $\$ 2.21$ to $\$ 4.76$ per gallon, or by 215 percent. The optimal tax would reduce GHG emissions of passenger transportation by $37 \%$ and increase social welfare US\$132 per capita. Despite this social benefit, such dramatic increases might be widely evaded given fuel prices in Mexico City substantially higher relative to those in neighboring regions. Instead of raising the tax level to its socially optimal level, a more moderate fuel tax increase of $\$ 1$ per gallon could be preferable as it still achieves substantial welfare gains, about 60 percent of those from the optimal fuel tax.

Although higher fuel taxes help to internalize pollution and accident externalities, the largest source of efficiency gain they yield comes from a reduction in automobile congestion. In principle, a more efficient way to reduce congestion would be to impose per mile tolls on automobiles, assuming that such an instrument can be implemented in practice. If this policy were implemented instead of a fuel tax increase, our analysis suggests the optimal toll on auto mileage (averaged across all driving in the metropolitan area) is 20.3 cents per vehicle mile; this converts, at current fuel economy, to $\$ 3.50$ per gallon of gasoline used by autos. Again, a significant portion of the welfare gains under the optimum policy could be generated by a more modest policy change. For example, we estimate that the welfare gains from a toll of 6.0 cents per mile (approximately US\$1 per gallon) are still half of those from the much higher (optimized) toll.

As regards microbuses, we calculate the optimized toll per vehicle mile as 34.6 cents in our benchmark calculations. Although the imposition of this toll causes some increase in auto travel, overall road congestion falls. Nonetheless, welfare gains from this policy are modest relative to those from gasoline taxes or auto tolls.

As for public bus and rail, roughly speaking prices under existing fare subsidies (which amount to around 50 percent of average operating costs from the transit companies) are not dramatically different from optimal fares in our analysis. Furthermore, the modal shares for mass transit are modest relative to those for autos and microbus. Thus, welfare gains from reforming transit prices are small relative to those from other pricing reforms.

The rest of the paper is organized as follows. The next section lays out our analytical model and derives our optimal pricing and welfare formulas. Section 3 discusses our parameter assumptions. Section 4 presents the main quantitative results and sensitivity analysis. Section 5 briefly discusses the implications for transport infrastructure investment, and currant bias 
towards locking into road-intensive infrastructure. The final section discusses possible ways to help overcome practical and political obstacles to implementing economically efficient policy reforms.

\section{Analytical Model}

We adopt a model of urban passenger travel by private auto, private microbus, public bus and public rail (i.e. subway). To varying degrees, transportation vehicles and their fuels contribute to externalities from local and global pollution, accidents, and road congestion. The government sets fuel prices, public transit fares, and mileage tolls for private buses and autos subject to a budget constraint. Although, for tractability, the model is static, it implicitly encompasses long run, policy-induced changes in vehicle fuel economy and vehicle fleet composition. As usual, short-run responses would be less elastic.

We do not consider policies that vary by region within Mexico City, or by peak versus off-peak travel. Partly, this is because the data to do this disaggregation (for example, sub-region or time-of-day specific external costs, and the degree of traveler substitution between subregions and time of day) are not available. Moreover, our aim is to begin with a simple and transparent analysis to fully understand the aggregate impacts of major pricing reform options, before studying more refined policies that vary by space and time of day, and that may require a more detailed (and less transparent) transport network model. Given that our focus is on overall efficiency rather than distributional effects (see Section 5), we employ with a representative (rather than heterogeneous) agent framework (see Parry and Small 2008 for a discussion of this assumption in the study of urban transportation pricing policies). Thus we do not address efficiency or distributional effects that could arise with heterogeneous agents.

Our model also omits certain scale economies from expanding transit provision, which may justify fare subsidies (Mohring 1972), though we do include fixed costs for subways. Other scale economies include reduced passenger wait times at transit stops as service frequency increases with a larger transit system; reduced costs of accessing the transit system with expansion of the route network; and the opportunity for transit operators to save on vehicle operating costs by increasing the occupancy of transit vehicles (instead of supplying more vehicle miles). This also implies that we do not consider system-wide economies that can arise from combining modes in a coordinated system, e.g. microbuses operating on coordinated 
scheduled that feed subways. On the other hand, scale economies may be counteracted by a diseconomy to the extent that greater transit vehicle occupancy imposes crowding costs on passengers though longer delays while passengers board and alight, greater likelihood of standing, discomfort, etc. (Kraus 1991). However, we do not have the data to credibly estimate the net impact, let alone the magnitude, of these scale economies and diseconomies, and therefore they are excluded from our analysis.

Prior literature on environmental and transportation taxes emphasizes the potential importance of considering how these policies interact with factor market distortions created by the broader tax system, particularly tax distortions in the labor market. Specifically, the optimal (revenue-neutral) tax on a fuel or travel mode will exceed the level warranted on externality grounds if the fuel or travel mode is a relatively weak substitute for non-work time (see e.g., Bovenberg and Goulder 2002). However, the needed empirical information evidence to address this potential adjustment for Mexico City --particularly the substitution between (taxed) formal work effort and (untaxed) informal work in response to changing transportation prices and income taxes -- is not available. Therefore, broader fiscal interactions are also excluded from our analysis. Moreover, in the context of Mexico City, both labor market imperfections generally and the possibility of lower-income workers being priced out of access to formal sector employment with higher transit costs could affect optimal externality pricing. These factors also are excluded from our analysis.

A final caveat is that we focus only on economic efficiency and not the distributional incidence of tax reforms. A distributional analysis would require data on car ownership, fuel use, and transit patronage by income class as well as some measure of lifetime income for each class (which is thought to be a better measure of household wellbeing than annual income). Incidence studies for the United States typically find that fuel taxes are mildly regressive (e.g., Parry et al. 2006, pp. 11-12), though there has been little work on how creative recycling of fuel tax revenues might help to alleviate this concern or on how one might implement such recycling measures.

\subsection{Model Assumptions}

(i) Household utility. An agent, representing an aggregation over all individuals in the Mexico City metropolitan area, has utility function $U($.$) defined by:$ 


$$
U=u(X, M, T, \bar{E})
$$

$$
M=M\left(M^{A}, M^{M B}, M^{B}, M^{R}\right)
$$

$$
T=\sum_{i} \bar{t}^{i} M^{i}, \quad i=A, M B, B, R
$$

All variables are expressed in per capita terms, and a bar indicates a variable at the city level, perceived as exogenous by the individual traveler.

In (1a) function $u($.$) is quasi-concave and increasing in its first two arguments and$ declining in the other two arguments. $X$ is consumption of a general good, produced and sold in the formal sector. $M($.$) is sub-utility from passenger miles of travel. In (1b), this is increasing in$ $M^{A}$, passenger miles traveled by automobile (including taxi); $M^{M B}$, passenger miles traveled by private microbus (minibuses and $\mathrm{VW}$ buses); $M^{B}$, passenger miles traveled by larger, government-provided buses; and $M^{R}$, passenger miles traveled by government-provided rail. ${ }^{2}$ $M($.$) is quasi-concave, so alternative travel modes are imperfect substitutes at the aggregate level.$

$T$ is in-vehicle travel time spent in trains, buses, and cars, which implicitly lowers utility through reducing time available for leisure and activities in the informal sector. In (1c), total invehicle travel time is the average time per mile for mode $i$ (the inverse of vehicle speed), $t^{i}$, times total passenger miles traveled by that mode, and aggregated across all four travel modes.

Finally, $E$ is an index of non-congestion externalities. These encompass local pollution, which harms human health, reduces visibility, corrodes buildings, etc., and greenhouse gases, which reduce (future) utility through global warming and associated climate change. ${ }^{3} E$ also includes external costs of traffic accidents such as injury risks to pedestrians and possibly to victims in multi-vehicle collisions, property damages borne by third parties, etc. (some accident costs are internal, such as own-injury risks in single-vehicle crashes, and these are implicitly incorporated in $u()$.$) .$

(ii) Transportation inputs. We assume that vehicle miles change in proportion to passenger miles for all modes, that is, vehicle occupancy is fixed. ${ }^{4}$ Therefore, for analytical purposes, we do not

\footnotetext{
${ }^{2}$ We ignore light rail travel, as it accounts for 0.03 percent of passenger miles in Mexico City (IAPT, 2007).

${ }^{3}$ As usual, we view climate change externalities from a world (rather than local) perspective.

${ }^{4}$ This is reasonable for transit, given that we do not model scale economies and diseconomies from changes in vehicle occupancy. And although car-pooling may increase with higher auto taxes, we believe this would have little impact on our policy simulations.
} 
need to distinguish between passenger miles and vehicle miles (implicitly, vehicle miles is passenger miles divided by a parameter representing vehicle occupancy).

For convenience, we specify the supply-side of the transport system on an aggregate basis. The "production functions" for aggregate miles traveled by each mode are:

$$
\begin{aligned}
& M^{i}=M^{i}\left(K^{i}, F^{i}\right), \quad i=A, M B, B \\
& M^{R}=M^{R}\left(K_{F C}^{R}, K^{R}\right)
\end{aligned}
$$

In (2a), $K^{i}$ represents an aggregate of non-fuel inputs needed to run vehicles of type $i$. For buses, these include the number of vehicles in the fleet (expressed on a capacity-equivalent basis), which can be varied fairly easily in the medium term, as well as the manpower required to drive vehicles. For private autos, $K^{A}$ reflects only vehicle capital costs, as the value of motorists' own time is incorporated via $T$ in the utility function. For subways in (2b), we distinguish fixed factors associated with labor required to operate stations $K_{F C}^{R}$, from the variable inputs required for vehicle operation, $K^{R}$. Capital infrastructure for subways, namely track and stations, is excluded from $K^{i}$. Thus, we follow the usual practice of studying how best to price rail systems given existing infrastructure, without worrying about recovering previously sunk capital investments in current fares.

In (2a) $F^{A}$ and $F^{M B}$ denote aggregate gasoline used by autos and microbuses respectively, and $F^{B}$ denotes aggregate use of diesel fuel used by public bus. In (2b) we exclude fuels (associated with the electricity consumption of trains) because environmental costs from fuel use, when expressed on a per passenger mile basis, are very small, given the very high occupancy of trains with several cars (Parry and Small 2008).

We assume the production functions in (2a) are increasing, quasi-concave, and homogeneous of degree one. Thus, there are constant returns to scale in the supply of auto and bus vehicle miles, which seems a reasonable approximation (Small and Verhoef 2007, pp. 65). For a given amount of auto or bus mileage, a reduction in the amount of fuel and increase in other inputs represents a long-run shift in the fleet towards more fuel-efficient, but more capitalintensive vehicles (e.g., due to incorporation of advanced fuel saving technologies into newer vehicles). For (2b) we assume the supply of rail passenger miles is proportional to variable inputs (i.e., $d M^{R} / d K^{R}>0$ is constant), which seems reasonable. 
(iii) Transportation prices. The government imposes a per-mile tax of $\delta \geq 0(i=A, M B)$, which is uniform across the metropolitan area. The price of gasoline and diesel are given by $p^{G}$ and $p^{D}$, respectively; these prices are set by the government via state ownership of fuel production. ${ }^{5}$ For all vehicles, we normalize the price of other market inputs $K^{i}$ to unity. And for transit vehicles, we denote the fare charged per passenger mile by $p^{i}(i \neq A)$.

Microbus is provided by a large number of competitive enterprises. In the zero-profit equilibrium, passenger fares equal (constant) variable operating costs per mile, which include fuel costs, labor costs, capital costs, and taxes. Thus:

$$
p^{M B}=\left(p^{G} F^{M B}+K^{M B}\right) / M^{M B}+\delta^{M B}, \quad j=D, C
$$

(iv) Other production. All goods, fuels, and vehicles are produced under constant returns to scale with labor as the only primary input (implicitly, vehicle capital is an intermediate input produced with labor).

(v) Household constraints and optimization. Agents are subject to the following budget constraint, which equates income with spending on auto fuel, auto capital, auto taxes, transit fares, and the general market good (whose price is normalized to unity):

$$
I+\overline{G O V}=p^{G} F^{A}+K^{A}+\delta^{A} M^{A}+\sum_{i \neq A} p^{i} M^{i}+X
$$

Here $I$ is exogenous income (implicitly from a fixed amount of work effort). $\overline{G O V}$ is per capita government spending on a transfer payment to households. This closes the model by requiring that any increase or decrease in government revenue from changing transportation prices be received (or paid for) by households. ${ }^{6}$

Agents choose the general good, auto inputs, transit travel (and thereby travel times), to maximize utility (1) subject to the budget constraint (4) and the auto production function in (2a), taking unit travel times and external costs as given. This yields:

\footnotetext{
${ }^{5}$ The government is assumed to supply whatever fuel is demanded at these prices so there is no rationing of fuel.

${ }^{6}$ Any income effects on passenger travel from changes in the transfer payment are implicitly included in the calibration of travel demand responses below. These income effects are relatively minor given that spending on auto or transit travel represents a relatively minor fraction of the household budget constraint (Willig 1976).
} 


$$
\begin{array}{ll}
\frac{u_{M^{A}}+u_{T} t^{A}}{u_{X}}=p^{G} \frac{F^{A}}{M^{A}}+\delta^{A}, & \frac{u_{M^{i}}+u_{T} t^{i}}{u_{X}}=p^{i}, \\
\left(\frac{u_{M^{A}}+u_{T} t^{A}}{u_{X}}-\delta^{A}\right) M_{F^{A}}^{A}=p^{G}, & \left(\frac{u_{M^{A}}+u_{T} t^{A}}{u_{X}}-\delta^{A}\right) M_{K^{A}}^{A}=1
\end{array}
$$

where the denominator $u_{X}$ converts utils into consumption or monetary units. In (5a), the marginal private benefit from auto passenger mileage, net of the cost of travel time (i.e., the marginal value of time $-u_{T} / u_{X}$ multiplied by time per mile $t^{A}$ ), is equated with per mile fuel costs and any per-mile auto toll. In addition, the marginal private benefit from mass transit travel, less time costs, is equated with the per mile fare. In (5b), the extra mileage (or "marginal product") from auto fuels and auto vehicle capital $\left(M_{F^{A}}^{A}\right.$ and $\left.M_{K^{A}}^{A}\right)$, times the marginal private benefit from auto travel, net of travel time costs and the mileage tax, are equated with the fuel price and the price of vehicle capital, respectively.

(vi) Per unit travel times and external costs. We define the following:

$$
\begin{aligned}
& t^{i}=t^{i}(\tilde{M}), \quad \tilde{M}=\bar{M}^{A}+\beta^{M B} \bar{M}^{M B}+\beta^{B} \bar{M}^{B}, \quad i \neq R, \quad t^{R}=\bar{t}^{R} \\
& \beta^{M B}=\frac{\sum_{i \neq R} t_{M B}^{i} M^{i}}{\sum_{i \neq R} t_{A}^{i} M^{i}}, \quad \beta^{B}=\frac{\sum_{i \neq R} t_{B}^{i} M^{i}}{\sum_{i \neq R} t_{A}^{i} M^{i}},
\end{aligned}
$$

where $t_{M B}^{i}=d t^{i} / d M^{M B}$, etc.

Beginning with (6b), $\beta^{M B}$ and $\beta^{B}$ denote "passenger car equivalents" for microbus and bus. These reflect the addition to congestion (i.e. the increase in travel time for all passengers of road vehicles) from one extra passenger mile by a microbus or bus $\left(\sum_{i \neq R} t_{M B}^{i} M^{i}\right.$ or $\left.\sum_{i \neq R} t_{B}^{i} M^{i}\right)$, expressed relative to the additional congestion from one extra passenger mile by $\operatorname{car}\left(\sum_{i \neq R} t_{A}^{i} M^{i}\right)$. An extra vehicle mile by a bus adds more to congestion than an extra vehicle mile by a car (buses take up more road space and stop frequently). However, due to the much larger passenger occupancy of buses than autos, an additional passenger mile by bus may add less to congestion than an extra passenger mile by auto (in which case $\beta^{M B}$ and $\beta^{B}$ are less than one). 
In (6a), average travel time per mile for a road vehicle is an increasing function of passenger car equivalent mileage $\tilde{M}$. The latter is simply the sum of passenger miles across cars, microbuses, and public buses, where the latter are weighted by their passenger car equivalents. Train time per mile is taken to be constant, that is, running an additional train does not slow down other trains in the system.

Non-congestion external costs are given by:

$$
E=E\left(F^{G}, M^{A}, M^{M B}, M^{B}\right)
$$

where $E$ is weakly increasing in all its arguments and $F^{G}=F^{A}+F^{M B}$ is combined gasoline consumption from cars and microbuses. The partial derivatives of this function denote various marginal external damages (in utils). For example, $\partial E / \partial F^{G}$ is the marginal externality from gasoline use, reflecting $\mathrm{CO}_{2}$ and local emissions, while $\partial E / \partial M^{A}$ is the marginal external cost of traffic accidents from automobile mileage. Following an increase in the gasoline tax, the proportionate reduction in gasoline-related externalities exceeds the proportionate reduction in auto and microbus mileage-related externalities. This is because the former reflects both long run changes in average vehicle fuel economy, as well as reductions in vehicle mileage, while the latter reflects only changes in mileage (see Parry and Small 2005 for further discussion). In contrast, diesel fuel and public bus mileage always change in the same proportion in our analysis since diesel prices are fixed. Thus there is no need to decompose diesel fuel externalities from public bus mileage externalities; implicitly, they are both incorporated in $\partial E / \partial M^{B}{ }^{7}$

(vii) Government. The government is subject to the budget constraint:

$$
\begin{aligned}
& G O V=\sum_{i} \delta^{i} M^{i}+\delta^{G} F^{G}-K_{F C}^{R} \\
& \delta^{G}=p^{G}-\theta^{F G}, \quad \delta^{B}=p^{B}-\theta^{B}, \\
& \theta^{B}=\left(\theta^{F B} F^{D}+K^{B}\right) / M^{B}, \quad \theta^{R}=K^{R} / M^{R}
\end{aligned}
$$

${ }^{7}$ If new vehicles are subject to binding emissions per mile standards, then emissions of new vehicles are independent of fuel economy, because all vehicles meet the same standard regardless of their fuel economy. In practice, the decoupling of emissions from fuel economy is undermined to the extent that emissions control equipment deteriorates over the vehicle life, older vehicles (not initially subject to standards) are still in use, people can evade emissions inspections for in-use vehicles, and there are fugitive emissions from petroleum refining (Harrington 1997). We believe these factors are significant for Mexico City and therefore that assuming proportionality between local emissions and gasoline use is a reasonable approximation. 
In these equations, $\theta^{F G}$ and $\theta^{F B}$ denote a constant per unit cost incurred by a stateowned enterprise for producing gasoline and diesel fuel respectively (resource inputs, refinery and distribution costs, etc.). $\theta^{B}$ and $\theta^{R}$ are the (constant) marginal costs to the government of supplying a passenger mile for public bus and rail. They include (variable) capital and labor costs and, in the case of bus, fuel costs. ${ }^{8}$

$\delta^{G}$ is the (effective) gasoline excise tax charged to private vehicle operators. It equals the difference between the government-determined fuel price, and the unit production cost of the fuel. $\delta^{B}$ and $\delta^{R}$ reflect the difference between the fare for public bus and rail charged to passengers, and the marginal cost to the government agency of supplying passenger miles; these price wedges can be negative if transit fares are subsidized.

The budget constraint in (8a) equates the government transfer payment with revenues from policy variables, namely auto and microbus mileage tolls, profits to state-owned fuel producers, and passenger fares, less the variable and fixed costs of transit provision.

\subsection{Formulas for Optimal Policies and Welfare Effects}

We now discuss formulas for the optimal pricing of fuels and passenger travel by mode and for the welfare gains from policy reforms, for a given set of prices for other fuels and modes. We take policies one at a time (implicitly viewing them as alternatives), though our formulas clarify how the optimal level of one policy varies with the level of other policies. Here we go straight to the key equations; the analytical derivations are provided in Appendix A.

(i) Optimal gasoline tax. To start with, we discuss a formula for the marginal welfare effect from raising the gasoline tax. This formula is derived by totally differentiating the household's indirect utility function with respect to $\delta^{G}$, accounting for changes in external costs, in per unit travel times, and in GOV to maintain government budget balance. The formula is (Appendix A):

\footnotetext{
${ }^{8}$ Our model assumes the (state-run) fuel producer breaks even. More generally, if fuel is sold at a loss, there is a subsidy that partly counteracts the price-raising impact of the fuel tax. This would imply a (moderately) higher fuel tax than suggested by our calculations below. On the other hand, it is possible that microbus operators have some limited market power through market-sharing agreements. In this case, the optimum toll on microbus mileage would be (moderately) lower than suggested below.
} 


$$
\begin{aligned}
& \left(E^{G}-\delta^{G}\right)\left(-\frac{d F^{G}}{d \delta^{G}}\right)+\left(E^{A}-\delta^{A}\right)\left(-\frac{d M^{A}}{d \delta^{G}}\right)+\left(E^{M B}-\delta^{M B}\right)\left(-\frac{d M^{M B}}{d \delta^{G}}\right)+\Gamma_{G} \\
& \Gamma_{G}=\left(\delta^{B}-E^{B}\right) \frac{d M^{B}}{d \delta^{G}}+\delta^{R} \frac{d M^{R}}{d \delta^{G}} \\
& E^{G}=-u_{\bar{E}} E_{F^{G}} / u_{X} \\
& E^{k}=-u_{\bar{E}} E_{M^{k}} / u_{X}+E^{C O N G k}, E^{C O N G k}=-\beta^{k} \frac{u_{T}}{u_{X}} \sum_{i \neq R} t_{\widetilde{M}}^{i} M^{i}, k=A, M B, B, \beta^{A}=1
\end{aligned}
$$

We first define the new notation, before interpreting the main equation in (9a). In (9c), $E^{G}$ is the marginal external cost of gasoline, expressed in dollars. In (9d), $E^{k}$ is the marginal external cost of passenger miles by auto, microbus, or public bus. These include marginal accident costs, marginal congestion costs $E^{\text {CONGk}}$, and (for public bus) pollution costs from diesel fuel use. $E^{\text {CONGK }}$ is the increase in per passenger mile travel time for a road vehicle due to congestion caused by an passenger mile by auto, microbus, or public bus $\left(t_{\widetilde{M}}^{i}, \beta^{M B} t_{\widetilde{M}}^{i}\right.$, and $\beta^{B} t_{\widetilde{M}}^{i}$ respectively), multiplied by the corresponding passenger mileage for those modes, aggregated over modes, and multiplied by the marginal value of travel time.

Equation (9a) decomposes the welfare effect of an incremental increase in the gasoline tax into four components. First is the welfare change in the gasoline market, equal to the reduction in gasoline use, times the marginal external cost of gasoline net of the prevailing gasoline tax. The second and third terms in (9a) are the reduction in microbus and bus passenger miles (induced by higher gasoline taxes), multiplied by the marginal external cost of passenger travel for those modes, less any prevailing per mile tolls on those modes. Finally, $\Gamma_{G}$ in (9a) captures secondary welfare effects due to substitution out of auto and microbus into public bus and rail, though these effects are of minor importance in our simulations (given the small modal shares for public transport).

Equating (9a) to zero, we obtain the optimal (second-best) gasoline tax $\delta^{G^{*}}$ in cents per gallon:

$$
\begin{aligned}
& \delta^{G^{*}}=E^{G}+\left(E^{A}-\delta^{A}\right) \rho_{A G}+\left(E^{M B}-\delta^{M B}\right) \rho_{M B G}+\gamma_{G} \\
& \gamma_{G}=\left(E^{B}-\delta^{B}\right) \rho_{B G}-\delta^{R} \rho_{R G}
\end{aligned}
$$


(10c) $\rho_{j G}=\frac{d M^{j} / d \delta^{G}}{d F^{G} / d \delta^{G}}, \quad j=A, M B, B, R$

In (10c) the relative price coefficient $\rho_{j G}$ denotes the change in passenger mileage on mode $j$ per unit change in gasoline use, following an increase in the gasoline tax.

In (10a) the optimum gasoline tax equals the pollution cost per gallon of gasoline, plus the external cost per passenger mile for auto and microbus (net of any per mile tax) where each is multiplied by the (reduction) in passenger miles for that mode relative to the (reduction) in gasoline use. The $\gamma_{G}$ term captures the (empirically small) influence of transit cross-price effects on the optimal gasoline tax.

(ii) Optimal mileage toll for autos. Following a similar procedure to that above, the optimal tax per passenger mile on automobiles in cents per mile (for given prices of other modes and fuels), $\delta^{A^{*}}$, is (Appendix A):

(11a) $\delta^{A^{*}}=E^{A}+\left(E^{G}-\delta^{G}\right) \rho_{G A}+\left(E^{M B}-\delta^{M B}\right) \rho_{M B A}+\gamma_{A}$

(11b) $\gamma_{A}=\left(E^{B}-\delta^{B}\right) \rho_{B A}-\delta^{R} \rho_{R A}$

$$
\rho_{j A}=\frac{d M^{j} / d \delta^{A}}{d M^{A} / d \delta^{A}}, \quad j=M B, B, R ; \quad \rho_{G A}=\frac{d F^{G} / d \delta^{A}}{d M^{A} / d \delta^{A}}
$$

(The optimal auto toll can alternatively be expressed per vehicle by multiplying $\delta^{A^{*}}$ by auto occupancy and similarly for the microbus toll discussed below.) As noted, this toll represents a measure of marginal external costs per passenger mile under optimal internalization of externalities. The actual implementation of a per-mile charge involves a number of real-world complications addressed below.

In (11c) the relative price coefficients are now defined for an increase in the auto mileage toll (rather than the gasoline tax), and the denominator in these expressions is the own-price effect on auto mileage. In (11a) the optimal toll equals the marginal congestion/accident externality per auto passenger mile, plus the product of the marginal reduction in gasoline use and the marginal external cost of gasoline, net of the prevailing gasoline tax. The optimal auto toll is lower to the extent it encourages the diversion of travel onto microbus and there are positive external costs to microbus travel (net of any microbus tolls). Finally, $\gamma_{A}$ captures cross- 
price effects with public bus and rail that again play only a relatively minor role in the simulations.

The main difference between the auto mileage toll and the gasoline tax is that the mileage toll targets the congestion/accident externalities more directly because all of the behavioral response to the tax comes from reduced mileage (rather than part of it coming from improved fuel economy). In addition, microbus mileage may increase in response to the auto toll (given that microbuses are not tolled), while it declines in response to higher gasoline prices (which are passed forward into passenger fares).

(iii) Optimal toll for microbus. The optimal toll per passenger mile by microbus, $\delta^{M B^{*}}$, is (Appendix A):

$$
\begin{aligned}
& \delta^{M B^{*}}=E^{M B}+\left(E^{G}-\delta^{G}\right) \rho_{G M B}+\left(E^{A}-\delta^{A}\right) \rho_{A M B}+\gamma_{M B} \\
& \gamma_{M B}=\left(E^{B}-\delta^{B}\right) \rho_{B M B}-\delta^{R} \rho_{R M B} \\
& \rho_{j M B}=\frac{d M^{j} / d \delta^{M B}}{d M^{M B} / d \delta^{M B}}, \quad j=A B, B, R ; \quad \rho_{G M B}=\frac{d F^{G} / d \delta^{M B}}{d M^{M B} / d \delta^{M B}}
\end{aligned}
$$

These equations are analogous to those for the optimal auto mileage toll, with the relative price coefficients now defined with respect to an increase in the microbus toll. As discussed below, increased auto travel in response to higher microbus tolls (and therefore fares) can significantly affect the optimal microbus toll, given that auto absorbs a significant portion of diverted microbus passengers and the significant external costs per auto passenger mile.

(iv) Optimum fare for public bus and rail. The optimal fare per mile for public bus is (Appendix A):

$$
\begin{aligned}
& p^{B^{*}}=\theta^{B}+E^{B}+\left(E^{A}-\delta^{A}\right) \rho_{A B}+\gamma_{B} \\
& \gamma_{B}=\left(E^{G}-\delta^{G}\right) \rho_{G B}+\left(E^{M B}-\delta^{M B}\right) \rho_{M B B}-\delta^{R} \rho_{R B} \\
& \rho_{j B}=\frac{d M^{j} / d \delta^{B}}{d M^{B} / d \delta^{B}}, \quad j=A, M B, R ; \quad \rho_{G B}=\frac{d F^{G} / d \delta^{B}}{d M^{B} / d \delta^{B}}
\end{aligned}
$$

The optimal fare consists of the marginal cost of supplying passenger miles, plus any external cost per passenger mile for bus travel. In addition, the fare is lower to the extent that reducing it would divert people from autos onto public bus (and external costs from auto mileage 
exceed any auto mileage toll). The fare also depends on (empirically minor) cross-price effects on fuels and other transit modes, as captured in the $\gamma_{B}$ term.

The optimal fare for rail is essentially analogous to that for public bus. However, unlike in (13a), there are no external costs for rail, while in the analogous expression to (13b) the crossprice effect on public bus, $\left(E^{B}-\delta^{B}\right) \rho_{B R}$, now includes external costs. ${ }^{9}$

(v) Functional forms. We take accident costs per mile and pollution costs per unit of fuel as given. However, we allow marginal congestion costs to fall as policies discourage road traffic. For the time to travel a passenger mile by auto we adopt the following formulation:

$$
t^{A}=\alpha\left\{1+\gamma\left(\frac{\tilde{M}}{\widetilde{M}^{0}}\right)^{4}\right\}
$$

where $\alpha$ is the time per mile by auto at free flow traffic speeds and $\gamma$ is a parameter. Under this formulation, average delay per mile due to congestion over free flow speeds is $\alpha \gamma\left(\tilde{M} / M^{0}\right)^{3}$, and marginal delay is $4 \alpha \gamma\left(\tilde{M} / M^{0}\right)^{3}$, so marginal delay is four times average delay. ${ }^{10}$ This formula is used to compute the (endogenous) marginal congestion costs for auto. Marginal congestion costs for microbus and public bus are also obtained from this formula, using their passenger car equivalents.

The own-price effects on fuel use and travel demand are determined by the constant elasticity specifications:

$$
\begin{aligned}
& F^{G}=F^{G 0}\left(\frac{p_{G}}{p_{G}^{0}}\right)^{\eta_{G G}} \\
& M^{A}=M^{A 0}\left(\frac{p_{G} F^{A} / M^{A}+\delta^{A}}{p_{G}^{0} F^{A 0} / M^{A 0}}\right)^{\eta_{A A}}, \quad M^{M B}=M^{M B 0}\left(\frac{p_{G} F^{M B} / M^{M B}+\delta^{M B}}{p_{G}^{0} F^{M B 0} / M^{M B 0}}\right)^{\eta_{\text {MBMB }}}
\end{aligned}
$$

\footnotetext{
${ }^{9}$ Note that relative price coefficients defined with respect to the price of public bus and rail implicitly account for feedback effects of road congestion. For example, raising the rail fare will divert people onto road, thereby exacerbating road congestion, which in turn partly offsets the added attractiveness of road travel when rail fares go up. These feedback effects are implicit in the choice of values for the $\rho$ s below.

${ }^{10}$ Equation (15) is known as the Bureau of Public Roads formula, which is widely used in traffic engineering models (see Lindsey and Verhoef 2000 for a review of literature on functional forms). The fourth power assumption seems reasonable, at least based on empirical relationships for Toronto and Boston discussed in Small (1992), pp. $70-71$.
} 


$$
M^{B}=M^{B 0}\left(\frac{p_{B}}{p_{B}^{0}}\right)^{\eta_{B B}}, \quad M^{R}=M^{R 0}\left(\frac{p_{R}}{p_{R}^{0}}\right)^{\eta_{R R}}
$$

where superscript 0 denotes an initial value.

In these equations, $\eta_{G G}$ denotes the own-price elasticity of gasoline demand, and $\eta_{A A}$, $\eta_{M B M B}, \eta_{B B}$ and $\eta_{R R}$ denote own-price elasticities for auto mileage, microbus mileage, public bus mileage, and rail mileage, respectively. In (16a) fuel demand is a simple function of fuel price relative to its initial level. In (16b), auto travel is a simple function of fuel costs, and possible congestion tolls, all expressed on a per mile basis, and relative to the initial price. The same applies for microbus mileage, given that fuel costs and tolls are passed forward into passenger fares. ${ }^{11}$ And in (16c) passenger miles by public bus and rail are a simple function of own transit fares.

As for cross-price effects, the effect on another mode $k$ following an increase in the price of mode $i$ is simply given by:

$$
M^{k}=M^{k 0}-\int_{p^{i 0}}^{p^{i}} \rho^{j i} \frac{d M^{i}}{d p^{i}} d p^{i}
$$

where the absolute price coefficient $d M^{i} / d p^{i}=\eta^{i i} M^{i} / p^{i}$ is calculated using (16) and assumed values for elasticities.

(vi) Welfare effects. The per capita welfare effect from a marginal increase in the gasoline tax, and a marginal increase in the auto toll, are, respectively (see Appendix A):

$$
\begin{aligned}
& \frac{1}{u_{X}} \frac{d u}{d \delta^{G}}=-\left(\delta^{G^{*}}-\delta^{G}\right) \frac{d F^{G}}{d p^{G}}=-\left(\delta^{G^{*}}-\delta^{G}\right) \frac{\eta_{G G} F^{G}}{p^{G}} \\
& \frac{1}{u_{X}} \frac{d u}{d \delta^{A}}=-\left(\delta^{A^{*}}-\delta^{A}\right) \frac{d M^{A}}{d \delta^{A}}=-\left(\delta^{A^{*}}-\delta^{A}\right) \frac{\eta_{A G} M^{A}}{p^{G}}
\end{aligned}
$$

In (18a), starting with the current gasoline tax, we can numerically integrate this expression, using the demand function in (16a), to obtain the welfare gain from any (non-marginal) increase

\footnotetext{
${ }^{11}$ Note that the impact of incremental increases in the fuel tax on mileage will decline somewhat as higher prices reduce fuel use per mile, via improved fuel economy. In addition, auto and microbus travel demands are not explicit functions of time costs per mile, which decline (moderately), with less traffic. That is, the feedback effect of less congestion on stimulating latent travel demand is implicitly taken into account in our chosen values for $\eta_{A A}$ and $\eta_{\text {MBMB }}$. This is consistent with the way these elasticities are typically estimated in the empirical literature.
} 
in the fuel tax. This welfare gain is illustrated in Figure 1 (for a linear demand curve-demand is slightly convex under our constant elasticity specification). The welfare gain is the shaded trapezoid area between the fuel price evaluated at the optimal gasoline tax $\left(p^{G}\left(t_{G}^{*}\right)\right)$, and the gasoline demand curve, with base equal to the reduction in gasoline. Similarly, using (18b) and (16b) we can integrate over marginal price effects to calculate the welfare effect from a nonincremental auto toll. Welfare gains from microbus tolls and changes in public bus and rail fares can be obtained in analogous ways.

Figure 1: Welfare Gain from Raising the Gasoline Tax

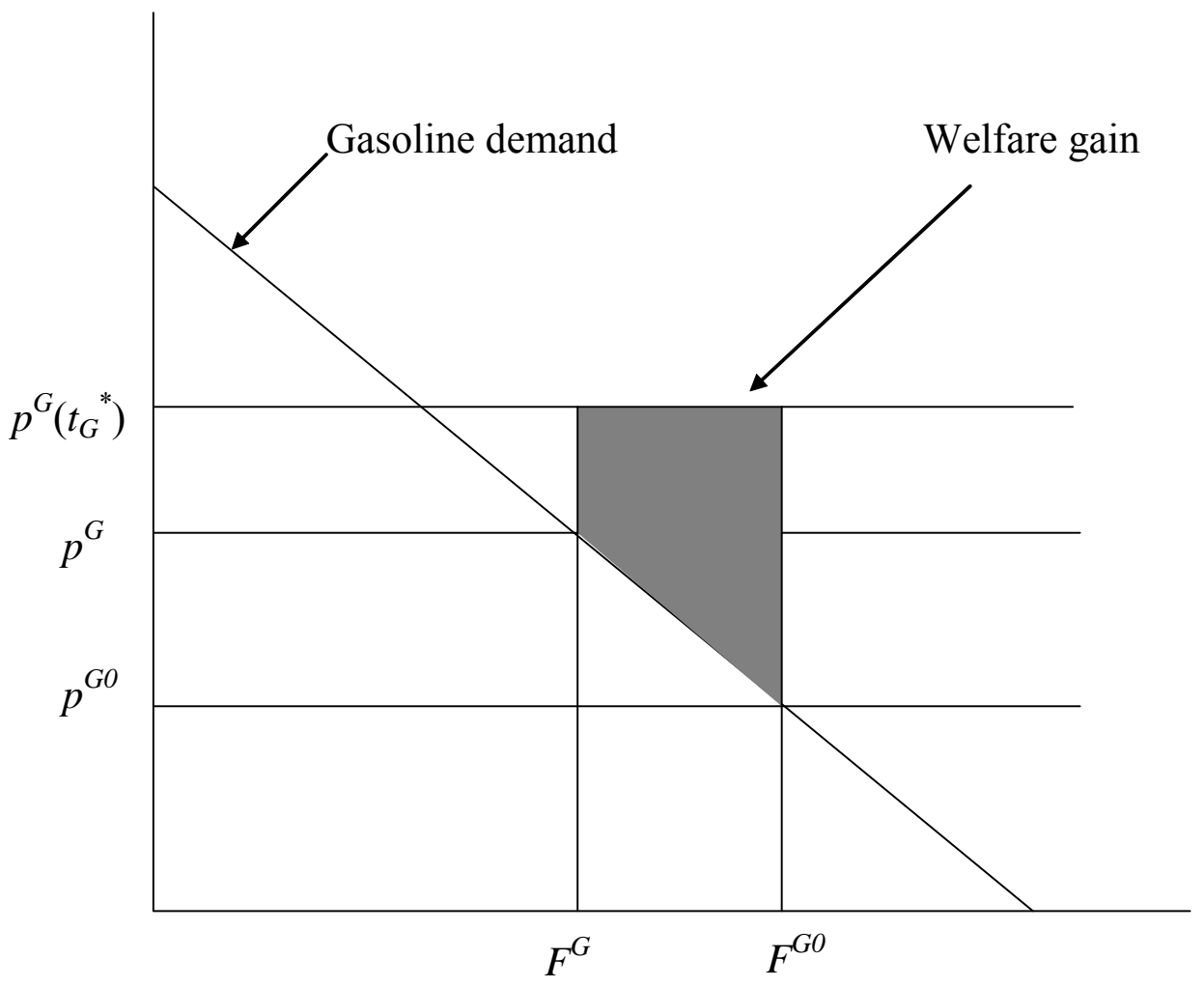

\section{Data}

Appendix B provides an extensive discussion of data sources and various estimation procedures for all parameters needed to compute the above formulas. Here we comment on selected baseline data, which is for year 2005, or thereabouts, and is summarized in Table 2. We express monetary figures in US dollar values for year 2005. They are easily converted to local currency using the (average) 2005 exchange rate of 10.90 Mexican pesos per US dollar. 
We caution against taking the baseline parameter assumptions and later simulation results too literally. For one thing, direct estimates of external costs and behavioral responses to transportation policies for the Mexico City region are sparse. Therefore, often we need to extrapolate evidence from other countries (notably the United States). While providing reasonable first-pass estimates, ideally these measures need to be checked against future empirical studies employing data on local factors. Another caveat is that we have less confidence in the marginal welfare effects of price changes at price levels that are very different from those currently prevailing, due to uncertainty over functional form relationships. Thus, our results from our base case parameter assumptions are meant to provide only a ballpark sense of optimal policies and the appropriate direction of policy reform. The implications of alternative parameter values are illustrated in a later sensitivity analysis.

\subsection{Basic Data for the Transport Network}

Most of this data comes from the Millennium Cities Database for Sustainable Transport (IAPT, 2001). In 2005, the per capita passenger mileage aggregated across all modes was 5,588 miles. 67 percent of this mileage was by private auto (and taxi), 19 percent by microbus, 7 percent by larger public buses, and 8 percent by subway. Vehicle occupancies are 1.6 people for autos, 8 for microbuses, 31 for public buses, and 174 for trains (which pull several cars). All these figures are for the entire metropolitan area of Mexico City, including the suburbs. (For the downtown core alone, the share of mileage by the three mass transit modes, as well as vehicle occupancies, would be larger.)

Average vehicle fuel economy for autos is 17.4 miles per gallon. The baseline fuel economy for microbuses and public buses is approximately one-half and one-quarter of that for autos. However, when expressed in terms of passenger miles rather than vehicle miles, fuel economy is far greater for buses than for autos, due to their much larger passenger occupancies. Overall gasoline consumption per capita is 149 gallons, with 88 percent of this used by autos and 12 percent by microbus.

The excise tax on gasoline was 17 cents per gallon in 2005, when retail fuel prices were $\$ 2.21$ per gallon. Thus the tax was less than 8 percent of the price. This tax rate is very low relative to rates typically levied in European countries (Parry et al. 2007, Figure 2), and even in the United Sates where the (federal and state) tax is currently 40 cents per gallon. In fact the tax 
was progressively reduced to partly dampen the impact of higher world oil prices on the retail fuel price; only three years earlier the tax had been 87 cents per gallon.

Table 2: Selected Parameter Assumptions for the Baseline Simulations

\begin{tabular}{|c|c|c|c|c|c|}
\hline & \multicolumn{5}{|c|}{ Mileage parameters } \\
\hline & Auto & Minibus & Bus & Rail & $\begin{array}{l}\text { Total or } \\
\text { average }\end{array}$ \\
\hline Annual passenger miles per capita & 3,723 & 1,067 & 371 & 427 & 5,588 \\
\hline Annual vehicle miles per capita & 2,296 & 139 & 12 & 2 & 2,449 \\
\hline Average vehicle speed, mph & 14.3 & 10.5 & 11.4 & 20.5 & 14.1 \\
\hline Average vehicle occupany & 1.6 & 8 & 31 & 174 & 2.3 \\
\hline Current fares or tolls, cents per passenger mile & na & 6.0 & 6.0 & 4.0 & \\
\hline Marginal operating cost, cents per passenger mile & na & 6.0 & 10.5 & 6.8 & \\
\hline Vehicle miles per gallon & 17.4 & 7.8 & 4.3 & & 16.8 \\
\hline Passenger miles per gallon & 28.3 & 60.1 & 131.6 & & 39.1 \\
\hline \multicolumn{6}{|l|}{ Marginal external costs } \\
\hline Congestion, cents per vehicle mile & 27 & 81 & 136 & 0 & 30.7 \\
\hline Congestion, cents per passenger mile & 17 & 11 & 4 & 0 & 13.4 \\
\hline Accidents, cents per vehicle mile & 1.9 & 1.9 & 1.9 & 0 & 1.9 \\
\hline Accidents, cents per passenger mile & 1.2 & 0.2 & 0.1 & 0 & 0.8 \\
\hline total, cents per passenger mile & 17.9 & 10.8 & 4.5 & 0 & 14.3 \\
\hline local and global pollution, cents per passenger mile & 3.5 & 1.5 & 0.8 & 0 & 2.7 \\
\hline total external cost, cents per passenger mile & 21.4 & 12.3 & 5.2 & 0 & 17.0 \\
\hline \multicolumn{6}{|l|}{ Mileage elastcities } \\
\hline own mileage elasticity wrt own fuel price or fare & -0.30 & -0.30 & -0.5 & -0.3 & \\
\hline \multicolumn{6}{|l|}{ Relative price coefficients for mileage } \\
\hline Fraction of reduced auto travel going to mode & na & 0.46 & 0.16 & 0.18 & \\
\hline Fraction of reduced microbus travel going to mode & 0.35 & na & 0.16 & 0.19 & \\
\hline Fraction of reduced bus travel going to mode & 0.35 & 0.25 & na & 0.10 & \\
\hline Fraction of reduced rail travel going to mode & 0.35 & 0.26 & 0.09 & na & \\
\hline Fraction of reduced auto/microbus travel going to other mode & na & na & 0.28 & 0.32 & \\
\hline \multicolumn{6}{|c|}{ Gasoline parameters } \\
\hline Fuel use, gallons per capita & 149.4 & & & & \\
\hline Current (effective) fuel tax, c/gal. & 17 & & & & \\
\hline Retail price of fuel, c/gal. & 221 & & & & \\
\hline \multicolumn{6}{|l|}{ External cost per gallon } \\
\hline Local pollution, cents per gallon & 90 & & & & \\
\hline Global pollution, cents per gallon & 9 & & & & \\
\hline total & 99 & & & & \\
\hline Own-price fuel elasticity & -0.60 & & & & \\
\hline
\end{tabular}

Notes. Figures are for year 2005 or thereabouts. All monetary data (prices, taxes, externalities, operating costs, etc.) are expressed in US dollars. See text and Appendix for details. Since emissions resulted from electricity generation are accounted for in the electricity sector and electricity sector specific policy instruments are normally implemented to reduce the emissions, we have not accounted for those emissions in the transport sector to avoid double counting. 


\subsection{External Costs}

The Mexico City basin is especially prone to local air quality problems, given its high altitude, and that it is surrounded by mountains on three sides, which limits pollution dispersion. We assume that local pollution damages per gallon of gasoline amount to 90 cents per gallon, where the huge bulk of the damage reflects mortality risk. This figure is based on a compromise between two sources. First, an extrapolation from a study for Los Angeles (another region with topography and climate especially favorable to pollution formation) by Small and Kazimi (1995), adjusting for differences in population exposure, the value of health risks, and vehicle emission rates between the two regions. Second, is a study of the health benefits from reducing future pollution concentrations in Mexico City (and two other cities) by Bell et al. (2006), based on pooling epidemiological evidence and the valuation of health risks from a variety of different sources (we consider only their mortality effects). As in other studies, we assume the health/environmental damages per gallon are the same for gasoline and diesel (see Appendix B).

From the mainstream climate damage assessment literature, we assume the damage cost per ton of $\mathrm{CO}_{2}$ is $\$ 10$, which converts to 9 and 11 cents per gallon of gasoline and diesel respectively (given the carbon content of these fuels). A few studies estimate far larger damages either because they employ much lower discount rates, or because they assume a risk of arbitrarily large damages (e.g. through a climate feedback effect causing extreme warming). We therefore consider other values later.

Marginal congestion costs for autos are put at 17 cents per passenger mile. As discussed in Appendix B, this is based on observed travel delays of 0.037 hours per mile (relative to travel times under free flowing traffic), equation (15), and evidence suggesting the value of travel time is about half the market wage, currently about $\$ 4$ per hour. (Using these figures, and annual mileage, also gives our figure in the introduction of $\$ 580$ in congestion costs per capita). In addition, parameter $\gamma$ in equation (15) is taken to be 1.121; this implies, for example, that a 20 percent reduction in road traffic will lower average travel times by 26 percent. For microbus and public bus we assume passenger car equivalents of 3 and 5 respectively (again, based on US studies). However, given much higher occupancies of transit vehicles, marginal congestion costs per passenger mile are computed at 11 and 4 cents for microbus and public bus respectively. 
Accident costs are extrapolated from US studies (accounting for differences in accident rates). They are taken to be the same on a per vehicle mile basis for autos, microbuses, and public buses for reasons noted in Appendix B. On a per passenger mile basis accident costs are small (7 percent) relative to marginal congestion costs, reflecting the severe congestion in Mexico City.

\subsection{Behavioral Responses}

There is a substantial body of empirical work on the responsiveness of gasoline consumption and auto mileage to fuel prices for the United States and certain other industrialized countries (for surveys see e.g., Goodwin et al. 2004, Glaister and Graham 2002). Based on this evidence, and making some allowance for the greater responsiveness of auto mileage, given the wide array of alternative mass transit options in Mexico City, we assume a gasoline price elasticity of -0.6 , and auto and microbus passenger mileage/fuel price elasticities of -0.3 . These assumptions are broadly in line with the one study we aware of that estimates behavioral responses with Mexican data (Eskeland and Feyzioglu 1994). (As already noted, and discussed further below, applying economy-wide evidence on fuel price elasticities to fuel tax increases that are specific only to Mexico City is problematic, as this does not capture incentives for legally, or illegally, obtaining low-tax fuel from neighboring regions of the country).

Own-fare elasticities for passenger mileage by public bus and rail are taken to be -0.5 and -0.3 , again based on a body of empirical literature, largely for the United Sates (see Appendix B). To obtain the relative price coefficients when a toll is imposed on auto travel, we assume that 80 percent of the diverted passenger mileage away from auto will go onto other modes (according to their share in non-auto passenger travel) and 20 percent will reflect reduced overall travel demand. ${ }^{12}$ When the price of transit increases however, many travelers are limited in their ability to substitute into auto, given that only a minority of the population owns automobiles (IAPT, 2007). For this case we assume that 30 percent of diverted travel from the transit mode whose price is increased reflects reduced overall travel demand, and of the remaining 70 percent half goes to auto and half to other transit modes (again in proportion to

\footnotetext{
${ }^{12}$ For example, for reduction of 10.0 auto passenger miles in response to higher auto tolls, 4.5 passenger miles are diverted onto microbus, 1.6 to public bus, 1.9 to rail, and 2.0 reflects reduced overall travel demand.
} 
their share of mileage in other transit mileage). The same modal diversion ratios apply for fare reductions. Finally, when the price of auto and microbus both increase together following an increase in gasoline taxes, we assume that 40 percent of diverted travel reflects overall travel demand, with the remainder going to public bus and rail in proportion to their relative modal shares.

\section{Results}

We take each policy in turn and discuss its optimal level, and welfare gains from policy reform, under our baseline parameter assumptions. We then briefly comment on how the main results are affected by alternative parameter assumptions.

\subsection{Optimal Gasoline Tax}

Table 3 shows our computation of the (second-best) optimal tax on gasoline. The optimal tax is $\$ 2.72$ per gallon. Raising the gasoline tax to its optimal level would increase the retail gasoline price from $\$ 2.21$ to $\$ 4.76$ per gallon, or by 215 percent. At this stage of the analysis one should not interpret the calculation of the optimal tax as automatically implying that such a tax should be imposed. Clearly a number of other factors need to be considered. At this juncture, the calculation is more important for what it says about the high externalities associated with fuel use and driving, relative to the price of fuel.

Local pollution damages account for 90 cents, or 33 percent, of this optimal tax. Global warming damages account for only 9 cents, or 3 percent. Thus even if Mexico City incorporates global warming damages in the optimal tax, its impact on the optimal tax would be small.

The most important component is reduced congestion externalities due to the effect of higher fuel prices on deterring automobile use, which accounts for 131 cents, or 48 percent, of the optimal tax. Even though only half of the reduction in auto fuel use comes from reduced driving (as opposed to long run improvements in vehicle fuel economy), the congestion benefits still imply a relatively large efficiency gain, given the large size of the congestion externality. Reduced auto accidents contribute 18 cents to the optimal tax, or 7 percent. Reduced congestion/accidents from lower microbus mileage contributes 25 cents to the optimal tax, or 9 percent, reflecting the modest share of gasoline consumed by microbus (initially 12 percent). 
Finally, cross-price effects onto public bus and rail have a negligible impact on reducing the optimal tax. This reflects their modest modal shares and modest external costs per passenger mile (relative to externality benefits per passenger miles from autos).

Table 3: Benchmark Calculation of Optimal Gasoline Tax

\begin{tabular}{lcc}
\hline \hline Components & $\begin{array}{c}\text { Optimal tax } \\
\text { (cents per gallon) }\end{array}$ & $\begin{array}{c}\text { Contribution to } \\
\text { optimal tax (\%) }\end{array}$ \\
\hline Local pollution & 90 & 33.1 \\
Global pollution & 9 & 3.3 \\
Congestion for autos & 131 & 48.3 \\
Accidents for autos & 18 & 6.8 \\
Congestion/accidents for microbus & 25 & 9.2 \\
Substitution into other modes and fuels & -2 & -0.7 \\
\hline & & $\mathbf{1 0 0}$ \\
\hline
\end{tabular}

Raising the gasoline tax to its optimal level (i.e. increasing the retail gasoline price by 215 percent from $\$ 2.21$ to $\$ 4.76$ per gallon) would reduce fuel use and associated emissions (nitrogen oxides, hydrocarbons, $\mathrm{CO}_{2}$ ) by 37 percent, and increase estimated annual welfare by $\$ 132$ per capita (Figure 2). Such a high level increase in tax could be, however, politically sensitive. Moreover, people could attempt to evade high regional fuel taxes by driving to fill up their tank in a neighboring region with lower taxes, or alternatively, smuggling low-taxed fuel into Mexico City.

Our study also shows that lower taxes can still contribute significantly to correct the externalities. For example, 63 percent of the welfare gains under the optimal tax could be obtained by a more moderate increase in the fuel tax of $\$ 1$ per gallon. The reason for this is easily seen from Figure 1. Although the base of the welfare gain trapezoid increases with higher fuel taxes, this is partly offset because its average height is falling, so the welfare gain increase by less than in proportion to the tax increase. 
Figure 2: Welfare Gains and Fuel Reductions from Higher Gasoline Taxes

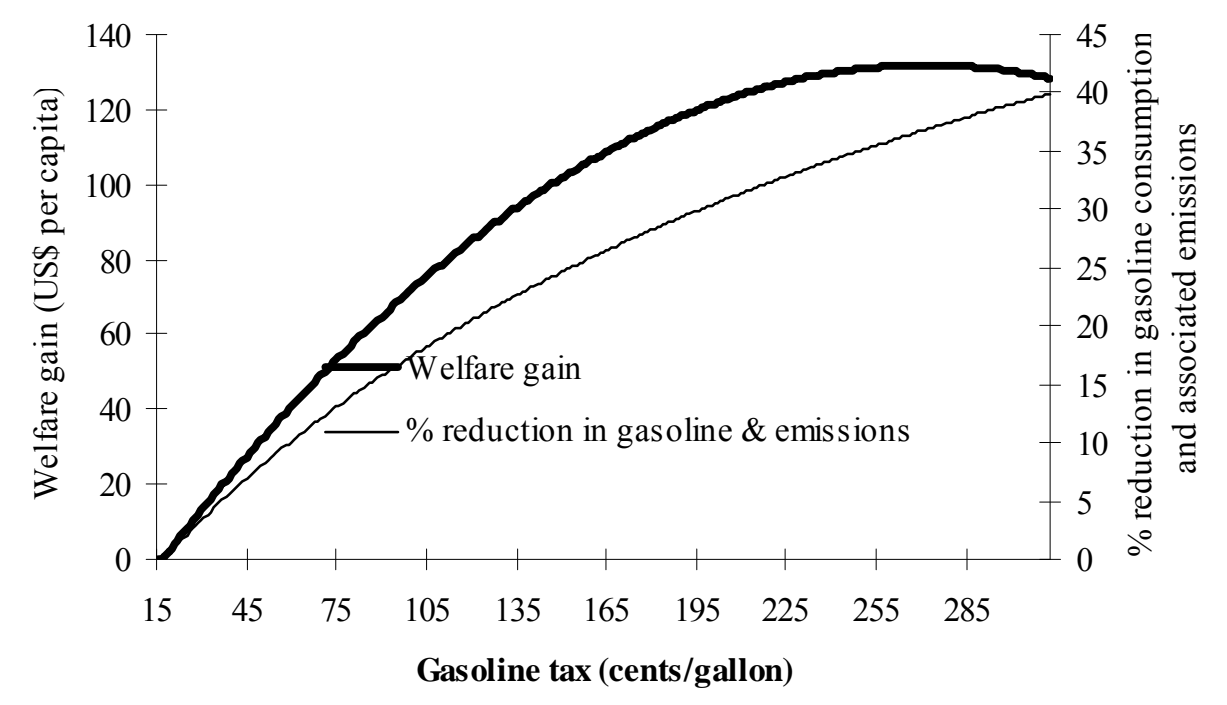

\subsection{Optimal Auto Toll Per Vehicle Mile}

Under the benchmark parameter assumptions, and with other taxes fixed at their current levels, the optimal auto mileage toll is 20.3 cents per vehicle mile (see Table 4). This is equivalent to 12.7 cents per passenger mile, or a fuel tax increase (for autos only) of $\$ 3.50$ per gallon at current auto fuel economy. Again, this very high charge rate needs to be seen initially as indicating the size of the relevant externalities, before turning to the question of what actual tax reforms should be undertaken. Local and global pollution justify a mileage toll equivalent to 71 and 7 cents per gallon respectively; these are somewhat lower than marginal pollution damages per gallon, because of partially offsetting pollution, as auto drivers are diverted onto microbus. In addition, the currently prevailing fuel tax (net of extra fuel tax payments from microbus operators) is netted out of the optimal micro toll; this lowers the optimal toll by 0.8 cents per vehicle mile.

Congestion is the largest component, accounting for 16.9 cents per mile, or $\$ 2.95$ in equivalent fuel taxation. The congestion component is more than twice as large in the optimal 
mileage toll, as it is in the optimal gasoline tax. This is because all, rather than 50 percent, of the behavioral response to the mileage toll comes from reduced driving and lower congestion. For the same reason the accident component is also larger, 1.9 cents per mile, though it is easily dominated by the congestion component. On the other hand, substitution into microbus offsets some of the congestion benefits and lowers the optimal toll by 2.3 cents per mile. Substitution effects into public bus and rail are again too small to matter.

Table 4: Benchmark Calculation of Optimal Auto Toll

\begin{tabular}{|c|c|c|c|}
\hline \multirow[b]{2}{*}{ Componets } & \multicolumn{2}{|c|}{ Optimal tax } & \multirow[b]{2}{*}{$\begin{array}{l}\text { Contribution to } \\
\text { optimal tax (\%) }\end{array}$} \\
\hline & $\begin{array}{c}\text { cents per } \\
\text { vehicle mile }\end{array}$ & $\begin{array}{l}\text { equivalent increase } \\
\text { in gasoline tax } \\
\text { cents per gallon }\end{array}$ & \\
\hline Local pollution & 4.1 & 71 & 20.2 \\
\hline Global pollution & 0.4 & 7 & 2.0 \\
\hline Prevailing fuel tax & -0.8 & -13 & -3.8 \\
\hline Congestion for autos & 16.9 & 295 & 84.2 \\
\hline Accidents for autos & 1.9 & 33 & 9.5 \\
\hline Substitution into microbus & -2.3 & -40 & -11.4 \\
\hline Substitution into other modes and fuels & 0.1 & -2 & -0.6 \\
\hline Total & 20.3 & 350 & 100 \\
\hline
\end{tabular}

Implementing the optimal toll would reduce auto mileage and associated emissions by an estimated 24.8 percent, and generate per capita welfare gains of $\$ 109$. Like in the case of gasoline tax, the optimal toll would increase driving costs substantially (since it would be as big as imposing a fuel tax of $\$ 3.50$ per gallon). But again, a more moderate toll of 6 cents per mile (equivalent to about $\$ 1$ per gallon on auto fuel) would still generate a significant welfare gain, about $\$ 55$ per capita. This implies, as illustrated in Figure 3, that even the introduction of a more moderate level of toll would produce a large social benefit (i.e., welfare gain) by reducing negative transportation externalities.

Implementation of distance-related congestion charges would be extremely challenging in Mexico City, at least in the near future. Imposing a tax on the annual odometer mileage of vehicles registered in Mexico City would not make sense as it would stimulate massive efforts to roll back odometer reading; in addition, it would penalize any driving outside the city (on roads 
that are far less congested) and would encourage use of vehicles within Mexico City that are not registered, or registered elsewhere. ${ }^{13}$

\section{Figure 3: Welfare Gains and Mileage Reductions from Auto Mileage Tolls}

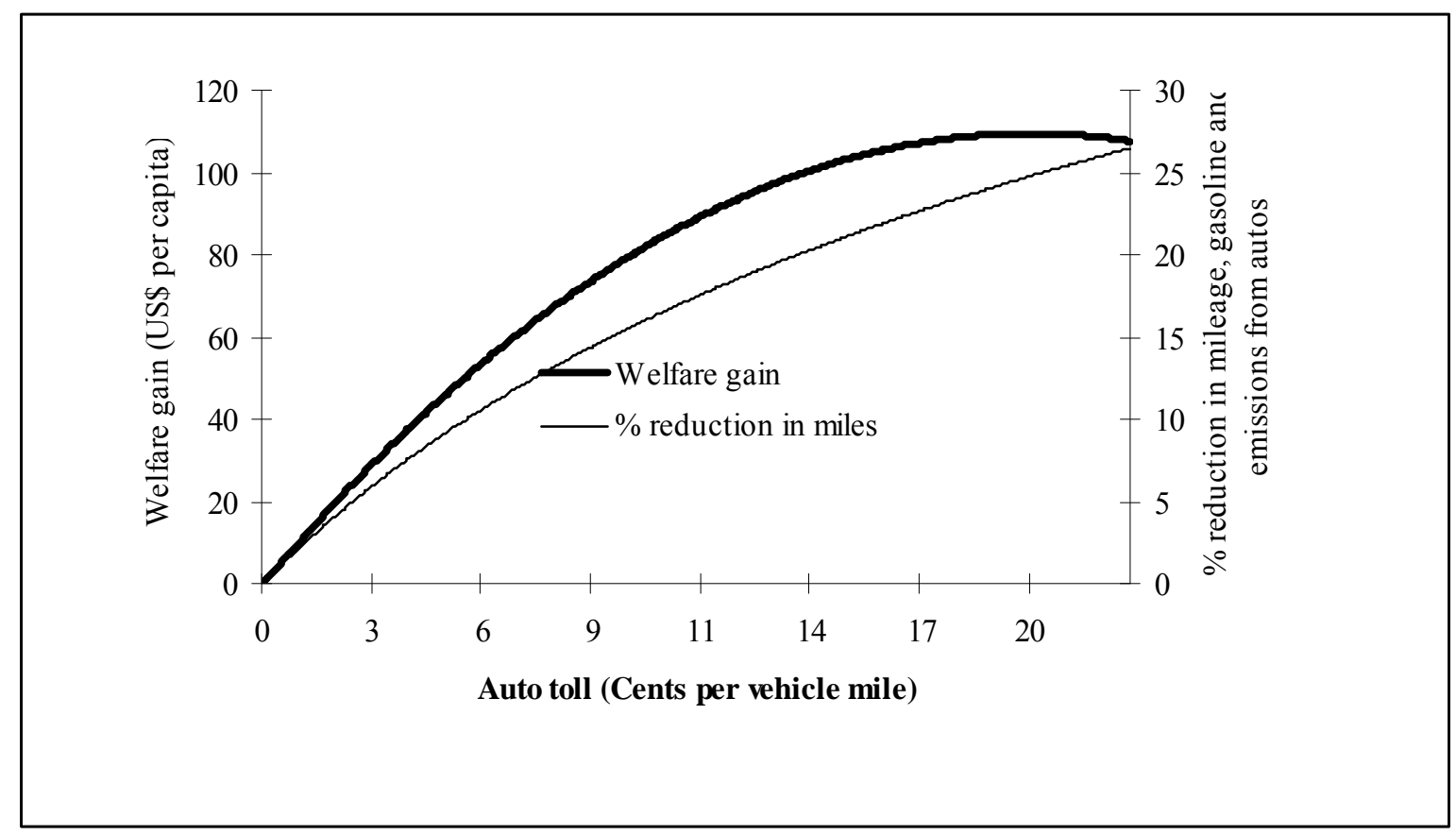

Another option might be to charge by the mile for any driving in Mexico City through global positioning systems (GPS), or other electronic tolling, such as transponders embedded in roads that record vehicles as they pass overhead. Mandating installation of the required metering technologies in vehicles is infeasible at present, given the large incentives for people to evade the mandate to avoid paying tolls as well as important privacy concerns. However, it might be possible to design schemes to circumvent these constraints. For example, owners of vehicles with the required metering technology might be eligible for a lump-sum annual rebate (financed in part by the new toll revenues). This subsidy could be set initially so that a large portion of

\footnotetext{
${ }^{13}$ Another option for congestion pricing is a cordon toll, as recently implemented in London and Stockholm. In the London scheme (Leape 2006), tag plates are photographed at all entry points into the priced area, and charges are automatically debited from the vehicle owner's pre-paid accounts (large fines are imposed for those who have not paid ahead of time). These schemes differ from the uniform mileage toll studied here. In particular, a worry is that they may worsen congestion outside of the priced area as people alter driving habits to avoid the toll, though this does not appear to have been a serious problem in London and Stockholm.
} 
drivers (those with lower than average annual mileage) gain by installing the technology (i.e. the subsidy payment exceeds their expected annual per mile charges). As the share of vehicles on the road that do not have metering technology progressively declines over time, it might become more feasible to phase in technology mandates for those remaining vehicles, to bring them into the pricing regime. All this presumes also the installation and maintenance of the required monitoring technology by the authorities.

\subsection{Optimal Microbus Toll Per Vehicle Mile}

As shown in Table 5, under our benchmark parameters, the optimal toll per vehicle mile for microbuses (with all other taxes at their initial levels) is 34.2 cents per vehicle mile. This is equivalent to a tax of $\$ 2.67$ per gallon of gasoline consumed by microbuses, at current microbus fuel economy - also a significant increase in the fuel charge. Microbus congestion by itself (and accidents) actually justifies a much larger toll of 79.8 cents per mile, given our assumption that microbuses contribute three times as much to congestion as autos per vehicle mile (again, note that congestion declines moderately in response to less microbus traffic ${ }^{14}$. However, there is an offsetting reduction of 46.2 cents per mile in the optimal toll as auto mileage expands to accommodate some of the displaced microbus passengers. ${ }^{15}$ Put differently, if we interpret the optimal toll as the measure of incremental benefits from reduced microbus congestion, a significant portion of that benefit is offset by increased auto use as a response to the lower microbus congestion. The contribution of pollution, even local pollution, is relatively small for calculating microbus tolls. In part, this is because 74 percent of the pollution benefits from reduced microbus travel are offset by more pollution from autos.

\footnotetext{
${ }^{14}$ Note however that in terms of passenger kilometer a microbus contribute less than one fourth of congestion created by an auto. Recall also that each mode operates independently as an imperfect substitute for others in this model. If microbus use also raised load factors in large buses and subways, or coordination of modes implied less total travel time, the resulting benefits would offset at least part of the optimal tax we calculate.

${ }^{15}$ For each reduced vehicle mile by microbus, 8 passenger miles are diverted, of which 2.8 go to auto, thereby increasing auto vehicle miles by 1.75 . Given an extra auto mile contributes one third of the congestion of an extra microbus mile, 58 percent of the reduced congestion from microbus is offset by increased auto travel.
} 


\section{Table 5: Optimal Microbus Toll per Vehicle Mile}

\begin{tabular}{lcc}
\hline \hline \multirow{2}{*}{ Componets } & \multicolumn{2}{c}{ Optimal tax } \\
\cline { 2 - 3 } & $\begin{array}{c}\text { cents per } \\
\text { microbus mile }\end{array}$ & $\begin{array}{c}\text { fuel tax } \\
\text { equivalent } \\
\text { (cents per gallon) }\end{array}$ \\
\hline Local pollution & 2.9 & 23 \\
Global pollution & 0.3 & 2 \\
Prevailing fuel tax & -0.6 & -4 \\
Congestion and accidents for microbus & 79.8 & 625 \\
Substitution with auto & -46.2 & -362 \\
Substitution with other modes and fuels & -2 & -16 \\
\hline & & $\mathbf{2 6 7}$ \\
Total & $3 \mathbf{3 4 . 2}$ & \\
\hline
\end{tabular}

The optimized microbus toll reduces microbus mileage by 21.2 percent. This generates a welfare gain of $\$ 8.6$ per capita, or only 6.5 percent of the welfare gains from optimizing the auto toll. Again, a large portion of the welfare gains can be obtained by far more moderate tolls. For example, a toll of 12 cents per microbus mile generates a welfare gain of $\$ 5.0$ per capita, or 58 percent of that from the optimized toll (see Figure 4). Here the key conclusion is that given our assumptions, a moderate increase in micro bus fare could help improve environmental quality and thus social benefits. 
Figure 4: Welfare Gains and Mileage Reductions from Microbus Tolls

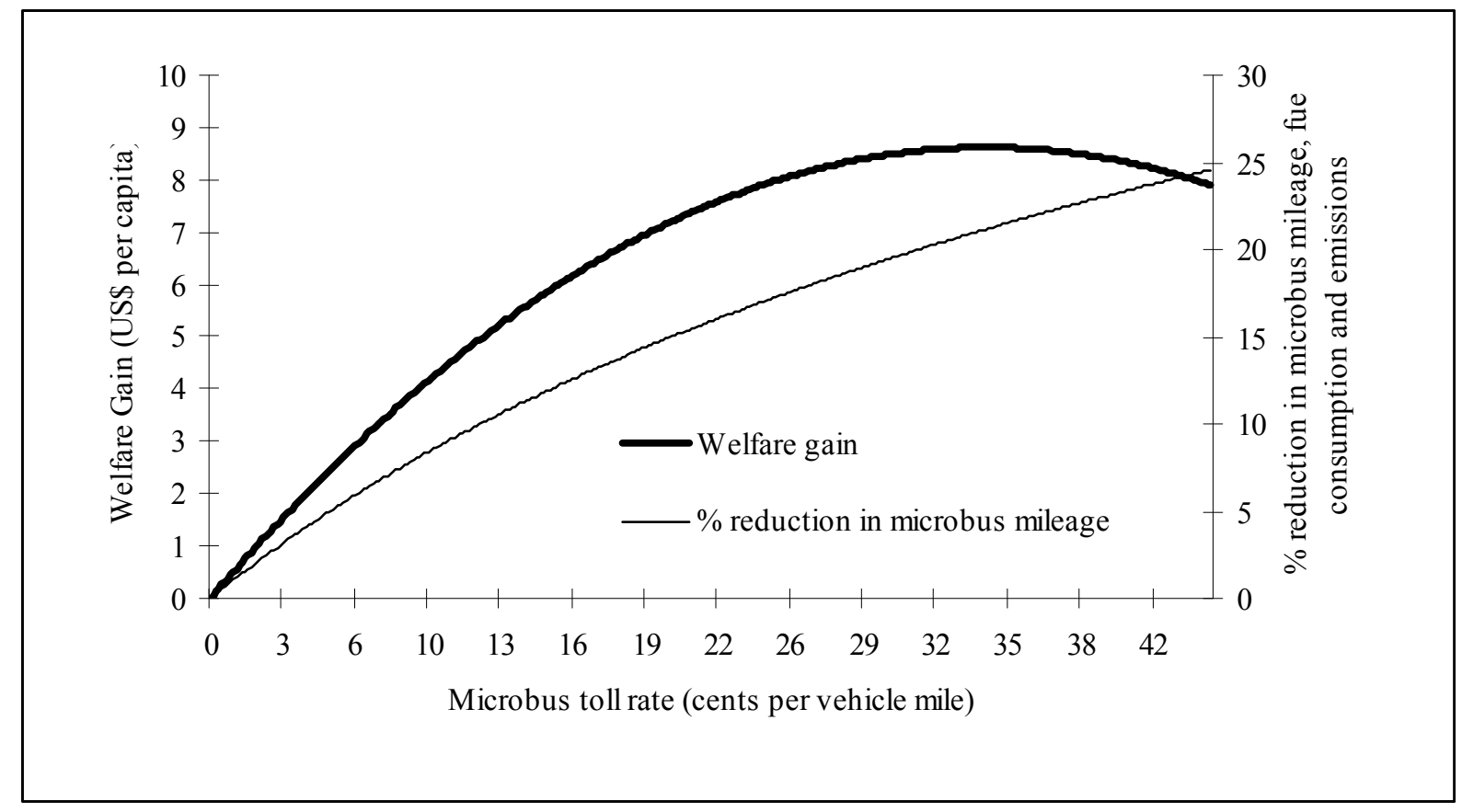

\subsection{Optimum Passenger Fare for Public Bus and Rail}

Table 6 shows the optimal fares for public bus and rail. For bus, diverting people off auto onto transit justifies a subsidy of 7.3 cents per passenger mile due to reduction of congestion and other externalities. And diverting passengers off other modes, particularly microbus, justifies a further subsidy of 3.4 cents per passenger mile. Counteracting this, the contribution of public buses themselves to pollution, accidents, and congestion adds 5.3 cents to the optimal fare. Overall, the optimum fare is 5.1 cents per passenger mile, about half the operating cost, and very close to the currently prevailing fare.

For rail, diverting passengers away from auto and other modes (especially microbus) justifies a similar subsidy of 11.4 cents per passenger mile. However, for rail there is no offsetting increase in externalities from extra travel by this transit mode, implying a wider difference between marginal supply costs per passenger mile and the optimum fare. ${ }^{16}$

\footnotetext{
${ }^{16}$ In fact, the optimum fare is actually negative in these simulations. In practice, of course, this subsidy could be difficult to target; one also would need to consider capacity constraints on rail travel.
} 


\section{Table 6: Optimal Fare for Public Bus and Rail}

\begin{tabular}{|c|c|c|}
\hline \multirow[t]{2}{*}{ Componets } & \multicolumn{2}{|c|}{ cents per passenger mile } \\
\hline & public bus & rail \\
\hline Marginal operating cost & 10.5 & 6.8 \\
\hline Local and global pollution (own mode) & 0.8 & 0 \\
\hline Accidents (own mode) & 0.1 & 0 \\
\hline Ccongestion (own mode) & 4.4 & 0 \\
\hline Substitution with auto & -7.3 & -7.3 \\
\hline Substitution with other modes and fuels & -3.4 & -4.1 \\
\hline Total & 5.1 & -4.6 \\
\hline Difference between optimum and current fare & -0.9 & -8.6 \\
\hline \multicolumn{3}{|l|}{ Welfare gain } \\
\hline From 1 cent change in fare towards optimum, $\$$ capita & 0.3 & 2.8 \\
\hline
\end{tabular}

We would not put too much emphasis on the precise numbers here, given the approximations and judgments used in gauging all the parameter values, and given that we ignore broader scale economies and diseconomies in transit provision. Nonetheless, the results do at least suggest that current fares might either be in the right ballpark or perhaps even too high; that is, our analysis suggests there would not be a strong efficiency case for scaling back current fare subsidies (see Parry and Small 2008 for more discussion of this for other urban centers). Moreover, when combined with the relatively modest modal shares of public bus and rail, the welfare gains from reforming transit prices are small relative to those from incorporating externalities in the cost of auto travel, in particular. This is underlined in the last row of Table 6 which shows that lowering current fares by one cent per passenger mile produces welfare gains of $\$ 0.3$ and $\$ 2.8$ per capita for public bus and rail respectively, which are small relative to the welfare gains from higher gasoline taxes. 


\subsection{Sensitivity Analysis}

Table 7 illustrates the sensitivity of optimal gasoline taxes, auto mileage tolls, and microbus tolls, to alternative values for selected parameters. We vary the pollution damages per gallon of gasoline, the marginal costs of road congestion, the mileage/fuel price elasticities for auto and microbus, the initial fuel economy for autos and microbuses, and the fraction of reduced demand in response to pricing one mode that comes from reduced overall travel demand (as opposed to substitution into other modes).

\section{Table 7: Sensitivity of Optimal Taxes to Alternative}

Parameters

\begin{tabular}{|c|c|c|c|}
\hline & $\begin{array}{l}\text { Gasoline tax } \\
\text { cents /gallon }\end{array}$ & $\begin{array}{c}\text { Auto toll } \\
\text { cents/vehicle mile }\end{array}$ & $\begin{array}{c}\text { Micobus toll } \\
\text { cents/vehicle mile }\end{array}$ \\
\hline Baseline value & 272 & 20.3 & 34.2 \\
\hline \multicolumn{4}{|c|}{ Pollution costs per gallon } \\
\hline doubled & 371 & 24.8 & 37.3 \\
\hline halved & 222 & 18.1 & 32.6 \\
\hline \multicolumn{4}{|c|}{ Marginal congestion costs } \\
\hline doubled & 373 & 32.6 & 67.7 \\
\hline halved & 213 & 12.4 & 17.0 \\
\hline \multicolumn{4}{|c|}{ Auto and microbus mileage/fuel price elasticity } \\
\hline-0.45 & 337 & 20.3 & 34.2 \\
\hline-0.15 & 198 & 20.3 & 34.2 \\
\hline \multicolumn{4}{|c|}{ Initial auto and microbus fuel economy } \\
\hline increased $25 \%$ & 308 & 18.7 & 33.5 \\
\hline reduced $25 \%$ & 234 & 22.0 & 35.3 \\
\hline \multicolumn{4}{|c|}{ Reduced overall travel demand } \\
\hline increased $25 \%$ & 273 & 20.5 & 39.9 \\
\hline reduced $25 \%$ & 272 & 20.0 & 28.5 \\
\hline
\end{tabular}


The results are sensitive to the parameter perturbations in Table 7 in some cases, but not in others. For example, when we double and halve (local and global) pollution damages per gallon of gasoline the optimal gasoline tax varies between \$2.22 and \$3.71 per gallon, while the optimal auto toll varies between 24.8 and 18.1 cents per vehicle mile. Similarly, doubling and halving marginal congestion costs causes the optimal gasoline tax to vary between $\$ 2.13$ and $\$ 3.73$ per gallon, the optimal auto toll to vary between 12.4 and 32.6 cents per vehicle mile, and the optimal microbus toll to vary between 17.0 and 67.7 cents per vehicle mile. Varying the mileage/fuel price elasticity affects the optimal gasoline tax, as this affects the congestion and accident benefits per gallon of fuel reduction. But it does not affect optimal mileage tolls. ${ }^{17}$ If vehicle fuel economy were initially greater than the optimal gasoline tax rises, as each gallon of gasoline not consumed is associated with a larger reduction in auto and microbus mileage, which magnifies the congestion benefits. On the other hand, higher initial fuel economy moderately lowers optimal mileage tolls, as there is less fuel and pollution saved, per unit reduction in mileage. Finally, results are only moderately sensitive to varying the fraction of reduced travel demand in response to pricing one mode that comes from reduced overall travel demand, as opposed to substitution across different modes.

\section{Implications for Transportation Infrastructure Investment}

Traditionally, infrastructure investment decisions are made based on comparing direct cost with perceived benefits. For economically efficient decision making, for infrastructure investment should be based on full costs (i.e., private plus external costs); hence estimating and seeking to account for external costs in considering alternative infrastructure investments is important for efficient allocation of scarce investment resources. This section briefly comments on the possible implications of the simulation results for infrastructure investment policy in Mexico City.

To the extent that infrastructure investment decisions are based on projections of usage of transportation systems that do not incorporate optimal pricing, there will be a bias towards spending on road expansion and maintenance projects and away from investments in the

\footnotetext{
${ }^{17}$ Varying the absolute values of the gasoline and mileage elasticities by the same proportion essentially has no effect on optimal taxes, as can be inferred from equations (10)-(12).
} 
metro/sub-urban railway system. This reflects the excessive use of automobiles, due to the under-pricing of pollution and road congestion externalities. For example, under the optimized automobile toll, estimated auto mileage would be cut by a quarter compared with current levels, and (given our assumptions for cross-modal effects) potential demand for rail travel would be increased by 150 percent. Besides facilitating a more efficient balance between road and rail projects in public investment decisions, higher charges for automobile travel would promote more efficient investment in private vehicle capital. At present, under-pricing of externalities results in a vehicle stock that is excessive in size, as well as biased towards older, and more polluting vehicles.

Investment allocation decisions are further complicated by the lock-in effect. This refers to a situation when previous long-lived investments may, after they are constructed, turn out to be inferior, in terms of full social costs, to other investment options; yet, due to high upfront capital costs, it is not worthwhile to scrap the original investment in favor of alternative new investments except in the long term. For example, if in the future, global climate change accelerates, policymakers may come to regret investments in carbon-intensive transport modes (i.e. roads) at the expense of lower-carbon modes (rail). In principle, this uncertainty over the future benefits and costs of different investment options could be handled by incorporating various option values into project evaluation (e.g., Pindyck 1991, 2007), though this would be challenging given the uncertainties surrounding global warming.

Even if emissions associated with electricity generation are account for, railways emit one of the least amounts of $\mathrm{CO}_{2}$ emissions per passenger kilometer travel among a broad range of alternative transportation modes (see Table 8).

Our analysis is far too aggregated to inform on the desirability of individual projects that expand rail service or other forms of mass transit at particular locations within the transportation system. The benefits of those projects in terms of reducing pollution and congestion depend on the extent to which they draw current road users onto the new rail or other mass transit extension, whether those passengers were driving through a particularly gridlocked part of the road system as opposed to driving across little-congested suburbs, and whether they formerly used private cars or microbuses. Nonetheless, if charges on automobile (and microbus) travel were to increase, the attractiveness of rail or other mass transit improvements in general across the Mexico City region would also increase. 
Table 8. Energy and $\mathrm{CO}_{2}$ Intensity by Mode

\begin{tabular}{l|c|c|c}
\hline \multicolumn{1}{c|}{ Mode } & Pass-mi/Gal & $\mathrm{CO}_{2} \mathrm{~g} /$ pass-mi \\
\hline Van Pool & 101.9 & 1,354 & 101 \\
Heavy Rail & 155.3 & 889 & 156 \\
Commuter Rail & 85.8 & 1,608 & 177 \\
Intercity Rail & 66.0 & 2,091 & 179 \\
Light Rail & 120.5 & 1,146 & 202 \\
Car - 1 Person & 27.7 & 4,983 & 371 \\
Car - Average Trip & 43.8 & 3,154 & 235 \\
Trolley Bus & 104.4 & 1,321 & 233 \\
Transit Bus & 32.5 & 4,245 & 299 \\
\hline
\end{tabular}

Notes

${ }^{\mathrm{a}}$ Passenger miles per Diesel Equivalent gallon

Highway Motor Coach: Vehicles designed for long-distance travel, and are characterized by "integral construction with an elevated passenger deck located over a baggage compartment".

Heavy Urban Rail: Self-propelled electric-powered passenger cars operating on an exclusive rail right-of-way, either below or aboveground.

Light Rail: Self-propelled electric-powered passenger cars operating on an exclusive or shared above-ground rail right-of-way .

Commuter Rail: Electric or diesel-powered locomotives pulling passenger cars, and operating on an exclusive rail right-of-way, for local short-distance travel.

Urban Transit Bus: Primarily diesel powered, rubber-tired vehicles for fixed route scheduled service.

Electric Trolley Bus: Electric-powered rubber-tired vehicles for fixed route scheduled service within an urban area. Van Pool: Small buses and other vehicles operating as a ride-sharing arrangement.

Source: ABA (2007).

An important caveat is that rail extensions in particular locations are not always substitutes for road travel. In dense commuting corridors, a metro system fed by trunk roads from the suburbs, could be appropriate to alleviate the largest bottlenecks. ${ }^{18}$ If congestion increases on complementary feeder roads, however, this needs to be taken into account in evaluating the rail upgrade. Similar concerns need to be addressed for light rail and bus rapid transit projects that may increase congestion in the corridors where they run, as well as on feeder roads. Assessing these factors requires use of more detailed models of the transportation network to predict changes in traffic flows throughout the system.

\footnotetext{
${ }^{18}$ For example, the Strategic Transport Plan for Dhaka, Bangladesh, initiated in 2004 recommended a mass rapid transit system that consists of three BRT routes, three metro lines and 50 roadways projects (Mahbubun Nabi, 2008). The Sao Paulo Transportation Plan includes strengthening both subway and surface transportation systems (Wilheim, 2004).
} 
Infrastructure lock-ins in the transport sector arise not only from the investment decisions for that sector, but also from regulatory and investment decisions on zoning and real estate development. Under the situation where automobile travel is under-priced relative to rail, neglecting externality costs, there is a danger that high-density development may preclude the future expansion of mass transit systems in ways which better account for environmental and congestion costs. This may particularly affect the feasibility of future surface rail and BRT systems, which require certain space and distance from residential concentrations. One approach to avoid such lock-ins is to leave vacant or thinly developed corridors for future transport infrastructure development (e.g., spaces left on both sides of the roads or spaces left in the middle of the two way traffic). This creates an "option value" by leaving open the possibility of constructing a transit corridor in the future, rather than permanently closing off that option. Proper land-use and zoning policies are required to address these lock-in issues (e.g., zoning laws that prohibit or limit construction and development in spaces that entail these options). Obviously, such limitations imply an economic loss in the present and near future years (the loss being the economic value of the activities and services that would emerge in the restricted zones). But that loss needs to be compared to the social gain, including the value of future pollution avoidance, should the option be exercised.

Large upfront capital costs are a key constraint against capital intensive transportation projects, particularly below-ground metros and heavy urban railways. For example, according to World Bank (2006) estimates, the capital costs involved in constructing the Line B metro in Mexico City amounted to $\$ 42.8$ million per kilometer of capacity (in US year $2002 \$$ ). ${ }^{19}$ In contrast, according to the same study, capital costs associated with constructing the Mexico City Bus Rapid Transit (BRT) system were a mere 4 percent of this figure, or $\$ 1.71$ million per added kilometer. Thus, BRT systems are becoming more popular than metro expansions. In addition, the external costs of bus systems, in terms of congestion, pollution, and accidents per passenger mile, while not zero, are still modest relative to comparable costs for automobiles (Table 2). The key conclusion here is that costs of public transport systems that do not appear to be economic per se may in fact be economic, or at least closer to economic (depending on the mode), once relative externality values are taken into account.

19 The B line was opened in year 2000. 25 percent of the line is tunnel, 20 percent is elevated, and 55 percent is surface level. 
Since capital costs for expanding urban roadways are lower than $\$ 1.0$ million per added kilometer, this factor needs to be considered when weighing alternatives for long-lived transportation system investments, especially if it is not possible for various reasons to implement first-best externality pricing. In that situation the residual (net) externalities avoided from the investments should be included in the economic evaluation of the projects. To the extent that even second-best pricing can be implemented, moreover, the resulting revenues may reduce the risks and costs associated with financing the infrastructure investments.

Despite the high costs, metro systems could be a solution to transportation problems in parts of mega-cities where a widespread expansion of surface transportation (e.g., roadways for BRT, light rail, surface railways) is physically constrained. This is because expansion of existing roadways or constructing surface railways would not be possible without dismantling large number of existing buildings, adding to the project cost the damage to existing properties. Some mega-cities, such as Bangkok and New Delhi, have recently constructed metros ${ }^{20}$. Moreover, urban railways/metro would be a key solution to divert commuters off the road network thereby alleviating auto congestion and pollution. Evaluations of proposed infrastructure investments that carefully account for changes in auto travel throughout the road network, and impacts on the broad range of transportation externalities (net of fuel and other taxes), are critical in this regard. $^{21}$

\section{Conclusions and Further Remarks}

Using a simple analytical and simulation model of aggregate welfare maximization, this study analyzes pricing instruments that could reduce passenger transportation externalities in the Mexico City Metropolitan Area. We focus on gasoline taxes, vehicle mileage tolls for

\footnotetext{
${ }^{20}$ Siemiatycky (2006) argues that the real driving force behind the Delhi metro is to show positive image or pride of having metro instead of need for the system to meet the city's transportation service demand.

${ }^{21}$ Urban railways may also raise the value of neighborhoods within close proximity, by lowering the transportation costs for people residing in these neighborhoods. For example, in the Greater Santiago area between December 2000 and March 2004, average apartment prices rose by an estimated 4.2 7.9 percent after new metro construction was announced and by 3.1 5.5 percent after the locations of the metro stations were identified (Agostini and Palmucci, 2008). Changes in property values may have important distributional implications which might be important to consider in a broader evaluation of rail investments that goes beyond pure economic efficiency impacts.
} 
automobiles and microbuses, and price reforms in public transit. We accounted for externalities from local air pollution, global warming, road accidents and traffic congestion.

Our study finds the optimal level of gasoline tax is $\$ 2.72 / \mathrm{gal}$, which is substantially higher than the current tax of $\$ 0.17 /$ gallon, and which would, if implemented, double the gasoline price. Although the optimal tax would reduce gasoline use and associated emissions by $37 \%$, increasing the tax to its socially optimal level would be difficult in practice as such a change in gasoline price has significant distributional implications and is politically sensitive. Moreover, drivers could evade high regional fuel taxes by driving to fill up their tank in a neighboring region with lower taxes, or alternatively smuggling low-taxed fuel into Mexico City. However, more than $60 \%$ of those welfare gains could be obtained by a more modest tax increase of $\$ 1 /$ gal.

The most important source of efficiency gains under higher fuel taxes would come from reduced road congestion. A far more efficient and direct way to reduce road congestion in principle would be to impose a mileage toll on auto travel. Although much higher tolls would be warranted based on the size of the external costs being addressed, a more moderate toll of around 6 cents per vehicle mile would capture three quarters of the potential welfare gains from a much larger toll. However, implementation of these policy instruments is a challenging task in Mexico City. Potential options for imposing millage charges (e.g., a tax on the annual odometer mileage of vehicles registered in Mexico City, global positioning systems or other electronic tolling), would also be difficult to enforce. Further studies are needed to examine how congestion charges could be applied in Mexico City.

The welfare gains from microbus tolls would be larger if they were imposed in tandem with auto tolls, as this lowers efficiency losses from the potential substitution from microbus to auto. The robustness of the optimal charges for the microbuses also depends on the extent to which they play an important role in generating economies of scale in a more integrated transit system. Although our treatment of public bus and rail is highly rudimentary, our results do at least suggest that any welfare gains from reforming fares for these transit modes are likely modest when compared with the far larger gains from reforming charges on auto travel.

Higher automobile fuel and travel taxes could substantially raise the potential demand for transit ridership, depending on the actual elasticities for switching modes and the sensitivity of 
private travel demand to the cost of driving. This has potentially important implications for the appropriate balance between road and mass transit infrastructure investment.

While the choice among alternative mass transit modes depends on specific circumstances, a robust conclusion is that in the absence of road travel pricing that adjusts for externalities, there will be the potential for too much investment in roads, too little investment in mass transit. While subsidies to mass transit users would help stimulate greater use of existing capacity, much more important, given the growing demand for travel generally, will be careful efforts to include the full social costs of travel in evaluating alternative infrastructure investments. A transit project that is "too costly" when considering direct costs could become more attractive when avoided pollution and congestion costs are taken into account. By similar reasoning, it will be very useful in future urban land use planning to leave corridors available for potential future expansion of mass transit, thereby increasing the economic returns by limiting damage to existing structures and public services.

\section{References}

American Bus Association (ABA), 2007. Comparison of Energy Use and $\mathrm{CO}_{2}$ Emissions from Different Transportation Modes. American Bus Association, Washington, DC.

Agostini, C. A. and G. A. Palmucci, 2008, "The Anticipated Capitalization Effect of a New Metro Line on Housing Prices", Fiscal Policy 29 (2): 233-256.

Bell, Michelle L., Devra. L. Davis, Nelson Gouveia, V1'ctor H. Borja-Aburto, and Luis A. Cifuentes, 2006. "The avoidable health effects of air pollution in three Latin American cities: Santiago, Sao Paulo, and Mexico City." Environmental Research 100: 431-440.

Borja-Aburto, V.H., D. Loomis, S.I. Bangdiwala, C.M. Shy, and R.A. Rascon-Pacheco, 1997. "Ozone, suspended particulates, and daily mortality in Mexico City." American Journal of Epidemiology 145: 258-268.

Bovenberg, A. Lans and Lawrence H. Goulder, 2002. "Environmental Taxation and Regulation." In Handbook of Public Economics. A. Auerbach and M. Feldstein eds. New York: North Holland.

BTS, 2004. National Transportation Statistics 2004. Bureau of Transportation Statistics, US Department of Transportation, Washington, DC. 
Burtraw, Dallas, Alan J. Krupnick, Erin Mansur, David Austin and Deirdre Farrell, 1998. "The Costs and Benefits of Reducing Air Pollutants Related to Acid Rain." Contemporary Economic Policy 16: 379-400.

De Borger, Bruno and Stef Proost, 2001. Reforming Transportation Pricing in the European Union: A Modelling Approach. Edward Elgar, Northampton, MA.

Davis, Lucas W., 2008. "The Effect of Driving Restrictions on Air Quality in Mexico City." Journal of Political Economy 116: 38-81.

DfT, 2004. Feasibility Study of Road Pricing in the UK-Report. United Kingdom Department for Transport, London.

Eskeland, Gunnar S., 1992. "Attacking Air Pollution in Mexico City." Finance and Development 29: 28-30.

Eskeland, Gunnar S., 1994. "A Presumptive Pigovian Tax: Complementing Regulation to Mimic an Emissions Fee.” World Bank Economic Review 8: 373-394.

Eskeland, Gunnar S. and Feyzioglu, Tarhan, 1995. "Rationing Can Backfire: The 'Day Without a Car’ in Mexico.” World Bank Policy Research Working Paper 1554.

Eskeland, Gunnar S. and Torben K. Mideksa, 2008. "Transportation Fuel Use, Technology and Standards: The Role of Credibility and Expectations." Policy Research Working Paper 4695, World Bank, Washington, DC.

Eskeland, Gunnar S. and Feyzioglu, Tarhan N. \& DEC, 1994. "Is Demand for Polluting Goods Manageable? An Econometric Study of Car Ownership and Use in Mexico." Policy Research Working Paper Series 1309, The World Bank.

FHWA, 2000. Addendum to the 1997 Federal Highway Cost Allocation Study Final Report. US Federal Highway Administration, Department of Transportation, Washington, DC.

Glaister, Stephen and Dan Graham. 2002. "The Demand for Automobile Fuel: A Survey of Elasticities." Journal of Transport Economics and Policy 36: 1-25.

Goodwin, P.B. 1992. "A Review of New Demand Elasticities with Special Reference to Short and Long Run Effects of Price Changes." Journal of Transport Economics and Policy: 26: 15569.

Goodwin, Phil B., Joyce Dargay and Mark Hanly, 2004. "Elasticities of Road Traffic and Fuel Consumption With Respect to Price and Income: A Review." Transport Reviews 24: 275-292.

Gurjar, B.R., T.M. Butler, M.G. Lawrence and J. Lelieveld, 2008. "Evaluation of Emissions and Air Quality in Megacities.” Atmospheric Environment 42 :1593-1606. 
Harrington, Winston, 1997. "Fuel Economy and Motor Vehicle Emissions." Journal of Environmental Economics and Management 33: 240-252.

IEA, 2006. Energy Prices and Taxes. International Energy Agency, Paris, France.

IMF, 2007. International Monetary and Financial Statistics. International Monetary Fund, Washington, DC.

IAPT, 2001. Millennium Cities Database for Sustainable Transport. International Association of Public Transport, Brussels.

INE, 2003. The Local Benefits of Global Air Pollution Control in Mexico City. Institutto Nacional de Ecologia, Mexico.

Kraus, Marvin, 1991. "Discomfort Externalities and Marginal Cost Transit Fares." Journal of Urban Economics 29: 249-59.

Lago, Armando M., Patrick D. Mayworm, and J. Matthew McEnroe, 1981. "Further Evidence on Aggregate and Disaggregate Transit Fare Elasticities." Transportation Research Record 799: $42-47$.

Leape, Jonathan. 2006. "The London Congestion Charge.” Journal of Economic Perspectives 20: $157-176$

Mayeres, Inge and Stef Proost, 2001. "Should Diesel Cars in Europe be Discouraged?" Regional Science and Urban Economics 31: 453-470.

Menckhoff, G., 2005. "Latin American Experience with Bus Rapid Transit." Paper presented in the Annual Meeting of Institute of Transportation Engineers, Melbourne, Australia, August 2005 .

Mohring, Herbert. 1972. "Optimization and Scale Economies in Urban Bus Transportation." American Economic Review 62: 591-604.

Molina, Luisa T. and Mario J. Molina, 2002. Air Quality in the Mexico Megacity: An Integrated Assessment. Kluwer Academic Publishers.

Mahbubun Nabi, A.S.M., 2008, "To Solve the Transportation Problem of Dhaka Metropolitan Area.” The Daily Star, June 14, 2008.

Nordhaus, William D., 2007. "A Review of the Stern Review on the Economics of Climate Change.” Journal of Economic Literature XLV686-702.

Nordhaus, William D. and Joseph Boyer, 2000. Warming the World: Economic Models of Global Warming. Cambridge, MA, MIT Press. 
O’Neill, M.S., D. Loomis, and V.H. Borja-Aburto, 2004. "Ozone, Area Social Conditions, and Mortality in Mexico City." Environmental Research 94: 234-242.

O'Ryan, R. and L. Larraguibel, L., 2000. Contaminacio' n del aire en Santiago: estado actual y soluciones. Documento de Tranbajo CEA No. 75. Universidad de Chile.

Parry, Ian W.H., and Kenneth A. Small, 2008. "Should Urban Transit Subsidies be Reduced?" American Economic Review, forthcoming.

Parry, Ian W.H., and Kenneth A. Small. 2005. "Does Britain or The United States Have the Right Gasoline Tax?” American Economic Review 95: 1276-1289.

Parry, Ian W.H., Margaret Walls and Winston Harrington, 2007. "Automobile Externalities and Policies.” Journal of Economic Literature XLV: 374-400.

Parry, Ian W.H., Hilary Sigman, Margaret Walls and Roberton C. Williams, 2006. "The Incidence of Pollution Control Policies." In Tom Tietenberg and Henk Folmer (eds.), The International Yearbook of Environmental and Resource Economics 2006/2007, Edward Elgar, Northampton, MA, 1-42.

Pindyck, Robert S, 1991. "Irreversibility, Uncertainty, and Investment." Journal of Economic Literature 29: 1110-48.

Pindyck Robert S, 2007. "Uncertainty in Environmental Economics." Review of Environmental Economics and Policy 1(1): 45-65.

Pratt, Richard H., Texas Transportation Institute, Cambridge Systematics, Parsons Brinkerhoff Quade \& Douglas, SG Associates, and McCollom Management Consulting. 2000. Traveler Response to Transportation System Changes: Interim Handbook. Transportation Research Board, Transit Cooperative Research Program Web Document 12 (March).

Safirova, Elena A., Sébastien Houde, and Winston Harrington, 2008. "Marginal Social Cost Pricing on a Transportation Network: Comparison of Second-Best Policies." Discussion paper 07-52, Resources for the Future, Washington, DC.

Sánchez, S., 2000. Air Quality Management Programs in the MCMA: Overview and Assessment. Report of the Third Workshop on Mexico City Air Quality, Cuernavaca, Mexico. MIT Integrated Program on Urban, Regional and Global Air Pollution Report No. 6, Cambridge, MA.

Siemiatycki, M., 2006, "Message in a Metro: Building Urban Rail Infrastructure and Image in Delhi, India." International Journal of Urban and Regional Research 30: 277-292.

Small, Kenneth A. 1992. Urban Transportation Economics. Fundamentals of Pure and Applied Economics, Volume 51, Harwood Academic Press, Chur, Switzerland.

Small, Kenneth A. and Erik T. Verhoef 2007. The Economics of Urban Transportation. Routledge, New York. 
Small, Kenneth A. and Kurt Van Dender, 2006. "Fuel Efficiency and Motor Vehicle Travel: The Declining Rebound Effect.” Energy Journal 28: 25-52.

Small, Kenneth A., and Camilla Kazimi, 1995. "On the Costs of Air Pollution from Motor Vehicles.” Journal of Transport Economics and Policy 29: 7-32.

Stern, Nicholas, 2007. The Economics of Climate Change. Cambridge University Press, Cambridge, U.K.

Tol, Richard S.J., 2007. "The Social Cost of Carbon: Trends, Outliers and Catastrophes." Economics Discussion Papers, No. 2007-44, Kiel Institute for the World Economy.

US DOE, 1996. Policies and Measures for Reducing Energy Related Greenhouse Gas Emissions: Lessons from Recent Literature. Report No. DOE/PO-0047, US Department of Energy, Office of Policy and International Affairs, Washington, D.C., July.

Vergara, W. and H. Haeussling, 2007. "Transport and Climate: Lessons from the Partnership between Mexico City and the World Bank" Latin America and Caribbean Region Sustainable Development Working Paper 29, The World Bank, Washington, DC.

Viscusi, W. Kip and Joseph E. Aldy, 2003. "The Value of a Statistical Life: A Critical Review of Market Estimates throughout the World.” Journal of Risk and Uncertainty 27: 5-76.

Weitzman, Martin L., 2008. "On Modeling and Interpreting the Economics of Catastrophic Climate Change.” Discussion paper, Department of Economics, Harvard University.

West, J.J., P. Osnaya, I. Laguna, J. Martinez, and A. Fernández, 2003. "Co-Control of Urban Air Pollutants and Greenhouse Gases in Mexico City." Final report to US National Renewable Energy Laboratory, subcontract ADC-2-32409-01.

West, Sarah and Roberton C. Williams, 2007. "Optimal Taxation and Cross-Price Effects on Labor Supply: Estimates of the Optimal Gas Tax." Journal of Public Economics 91: 593-617.

Wilheim, J., 2004. "Urban Planning: Innovations from Brazil." Working Paper, No. 11, Center for Latin American Studies, University of California, Berkeley.

Willig, Robert D., 1976. "Consumer's Surplus without Apology." American Economic Review 66: 589-97.

World Bank, 2001. World Bank Urban Transport Strategy Review. World Bank, Washington, DC.

World Bank, 2002a. Cities on the Move: A World Bank Urban Transport Strategy Review. World Bank, Washington, DC. 
World Bank 2002b. "Improving Air Quality in Metropolitan Mexico City: An Economic Valuation.” Policy Research Working Paper, WPS 2785.

World Bank, 2006. Cities on the Move: A World Bank Urban Transport Strategy Review. World Bank, Washington, DC.

Wright, L. and W. Hook, 2007, Bus Rapid Transit Planning Guide, 3rd edn. Institute for Transportation and Development Policy, New York. 


\section{Appendix A}

\section{Analytical Derivations}

Deriving Equation (9). From (1) and (4), the household's indirect utility function, $V$, is defined by:

$$
\begin{aligned}
V\left(\bar{t}^{A}, \bar{t}^{M B}, \bar{t}^{B}, \bar{E}, \overline{G O V}, p^{G}, \delta^{A}, p^{M B}, p^{B}, p^{R}\right) \\
=\underbrace{M a x}_{X, M^{A}, M^{M B}, M^{B}, M^{R}} u\left(X, M\left(M^{A}, M^{M B}, M^{B}, M^{R}\right), \sum_{i} \bar{t}^{i} M^{i}, \bar{E}\right) \\
+\lambda\left\{I+\overline{G O V}-p^{G} F^{A}-K^{A}-\delta^{A} M^{A}-\sum_{i \neq A} p^{i} M^{i}-X\right\}
\end{aligned}
$$

where $\lambda=u_{X}$ is the marginal utility of consumption. The solution to this problem yields the demand functions:

$$
M^{A}=M^{A}\left(\bar{t}^{A}, \bar{t}^{M B}, \bar{t}^{B}, \bar{E}, \overline{G O V}, p^{G}, \delta^{A}, p^{M B}, p^{B}, p^{R}\right)
$$

and so on for other travel demands and the general good.

Partially differentiating the indirect utility function gives:

$$
\begin{aligned}
& V_{\bar{t}^{i}}=u_{T} M^{i}, i=A, M B, B, R ; \quad V_{\bar{E}}=u_{\bar{E}} ; \quad V_{\overline{G O V}}=u_{X} ; \quad V_{p^{G}}=-u_{X} F^{A} ; \\
& V_{\delta^{A}}=-u_{X} M^{A} ; \quad V_{p^{i}}=-u_{X} M^{i}, i=A, M B, B, R
\end{aligned}
$$

Totally differentiating the indirect utility function with respect to $\delta^{G}$, using (A3), gives:

$$
\frac{1}{u_{X}} \frac{d V}{d \delta^{G}}=\frac{u_{T}}{u_{X}} \sum_{i=A, M B, B} \frac{d \bar{t}^{i}}{d \delta^{G}} M^{i}+\frac{u_{\bar{E}}}{u_{X}} \frac{d \bar{E}}{d \delta^{G}}+\frac{d \overline{G O V}}{d \delta^{G}}-F^{A}-M^{M B} \frac{d p^{M B}}{d \delta^{G}}
$$

From differentiating (6a):

$$
\frac{d t^{A}}{d \delta^{G}}=t_{\widetilde{M}}^{A}\left(\frac{d M^{A}}{d \delta^{G}}+\beta^{M B} \frac{d M^{M B}}{d \delta^{G}}+\beta^{B} \frac{d M^{B}}{d \delta^{G}}\right)
$$

and so on for increases in per unit travel times for microbus and public bus.

From differentiating (7): 
(A6)

$$
\frac{d \bar{E}}{d \delta^{G}}=\bar{E}_{F^{G}} \frac{d F^{G}}{d \delta^{G}}+\bar{E}_{M^{A}} \frac{d M^{A}}{d \delta^{G}}+\bar{E}_{M^{M B}} \frac{d M^{M B}}{d \delta^{G}}+\bar{E}_{M^{B}} \frac{d M^{B}}{d \delta^{G}}
$$

From differentiating (8a):

$$
\frac{d \overline{G O V}}{d \delta^{G}}=F^{G}+\delta^{G} \frac{d F^{G}}{d \delta^{G}}+\sum_{i} \delta^{i} \frac{d M^{i}}{d \delta^{G}}
$$

From differentiating (3):

(A8) $\frac{d p^{M B}}{d \delta^{G}}=\frac{F^{M B}}{M^{M B}}$

Substituting (A5)-(A8) into (A4), and collecting terms, gives expressions in (9).

Deriving (11). Totally differentiating the indirect utility function in (A1) with respect to $\delta^{A}$, and using (A3), gives:

$$
\frac{1}{u_{X}} \frac{d V}{d \delta^{A}}=\frac{u_{T}}{u_{X}} \sum_{i=A, M B, B} \frac{d \bar{t}^{i}}{d \delta^{A}} M^{i}+\frac{u_{\bar{E}}}{u_{X}} \frac{d \bar{E}}{d \delta^{A}}+\frac{d \overline{G O V}}{d \delta^{A}}-M^{A}
$$

Following the same steps as above, we obtain the analogous expression to that in equations ( $9 \mathrm{a}$ and $\mathrm{b})$ :

$$
\begin{aligned}
& \frac{1}{u_{X}} \frac{d V}{d \delta^{A}}=\left(\delta^{G}-E^{G}\right) \frac{d F^{G}}{d \delta^{A}}+\left(\delta^{A}-E^{A}\right) \frac{d M^{A}}{d \delta^{A}}+\left(\delta^{M B}-E^{M B}\right) \frac{d M^{M B}}{d \delta^{A}} \\
& +\left(\delta^{B}-E^{B}\right) \frac{d M^{B}}{d \delta^{A}}+\delta^{R} \frac{d M^{R}}{d \delta^{A}}
\end{aligned}
$$

Equating this expression to zero gives the optimal toll in (11a-c).

Deriving (12) and (13). The derivation of (12a-c), and of (13a-c), is analogous to that for (11) above.

Deriving (18). From (9a and b) and (10c) the welfare change from an incremental increase in the gasoline tax is:

(A11) $\frac{1}{u_{X}} \frac{d u}{d \delta^{G}}=$

$$
\left\{E^{G}-\delta^{G}+\left(E^{A}-\delta^{A}\right) \rho_{A G}+\left(E^{M B}-\delta^{M B}\right) \rho_{M B G}+\left(E^{B}-\delta^{B}\right) \rho_{B G}-\delta^{R} \rho_{R G}\right\}\left(-\frac{d F^{G}}{d \delta^{G}}\right)
$$

Substituting $\delta^{G^{*}}$ from (10a) gives (18a). Similarly, (18b) is obtained from (A10), (11a and c). 


\section{Appendix B}

\section{Details on Parameter Calculations and Data Sources}

Basic mileage, travel speed, and fuel data. All the data on passenger miles, vehicle miles, average vehicle speeds, and fuel use across the four travel modes comes from IAPT (2001). This data are adjusted for year 2005, just after the introduction of dedicated express bus lanes on the main north-south arterial route (which significantly reduced the number of microbuses). Data on auto vehicle miles includes 1,695 miles by private passenger car, 264 vehicle miles by ordinary taxi, and 337 vehicle miles by shared taxi. Data is available on passenger miles by auto but not by taxi. To obtain passenger miles for taxi we assume ordinary taxi carries on average 1.5 passengers and shared taxi carries 2.5 passengers.

Fuel prices and taxes. This data is taken from IEA (2006), pp. 198. Prices and taxes per gallon are for year 2005. The tax includes only the excise tax not the value added tax, as the latter applies to goods in general (rather than just to gasoline), and therefore does not raise the price of gasoline relative to other goods.

Marginal local pollution damages. We use various sources to infer a value for marginal pollution damages.

First, a widely cited study by Small and Kazimi (1995) put the damages from gasoline vehicles at 4 cents per mile, or 80 cents per gallon of gasoline, for 1992 in year 2000 dollars, for Los Angeles, where, as in Mexico City, meteorological and geographical characteristics are especially favorable to pollution formation. ${ }^{22}$ Damage estimates are easily dominated by mortality risks. We divide this figure by 4 to account for the lower value of statistical life (and therefore lower value of health risks) in Mexico City, where per capita income is about one-fourth of that in the United States. ${ }^{23}$ Population density in Mexico City is about six times that in Los Angeles (Molina and Molina 2002, Table 2.1). On the other hand, the population of Mexico City is younger, implying the average person might be less vulnerable to pollutioninduced illness. For example, the proportion of the population over 65 that is most at risk is half that in Mexico City compared with the United States (Molina and Molina 2002, Table 4.1), although it is

\footnotetext{
${ }^{22}$ Small and Van Dender (2006, pp. 104) put pollution damages at 30 cents per gallon for US urban areas in 2005. This lower figure mainly reflects the progressive tightening of emissions per mile standards on new vehicles.

${ }^{23}$ Studies suggest that the elasticity of the value of life with respect to income is unity or less (Viscusi and Aldy 2003).
} 
possible that younger people have a higher willingness to pay to avoid mortality risk. We scale up the damage estimate by 4 to make some allowance for (sensitivity-adjusted) population exposure to pollution. ${ }^{24}$ Thus, we are left with a damage estimate of 80 cents per gallon.

Second, a study by Bell et al. (2006) quantifies the health benefits from improving air quality in three Latin American cities, including Mexico City, based on pooling a variety of epidemiological evidence, both for the United States and Mexico City, as well as evidence on the willingness to pay to avoid health risks. We consider only their mortality effects. In their baseline case in 2020, the benefits of reduced mortality (valued by willingness to pay) from a reduction in pollution concentrations of 14 percent in Mexico City amounts to about $\$ 66$ per capita per year in current dollars (this assumes a population of 26 million in 2020 and baseline pollution concentrations of 40 percent greater than present levels). A reduction in gasoline demand of 35 percent, or 52 gallons per capita, would reduce particulate concentrations (the most important pollutant from a health perspective) by 14 percent, given that gasoline accounts for roughly 40 percent of particulate concentrations in the region, mainly through secondary pollutant formation (O'Ryan and Larraguibel 2000). Thus, the benefit per gallon reduction is \$1.26.

Erring slightly on the conservative side, we adopt a value of 90 cents per gallon of gasoline, as a compromise between the above two figures. ${ }^{25}$

We assume that the pollution damage per gallon of diesel fuel is the same as that for gasoline. Although the mix of local pollutants caused by combustion of the two fuels is somewhat different, estimates of the damages per gallon from diesel fuel combustion are roughly comparable to those for gasoline, at least for the United States (FHWA, 2000). ${ }^{26}$ The pollution cost for diesel is expressed on a per passenger mile basis for public bus by multiplying by bus fuel economy and dividing by bus occupancy.

Marginal global pollution damages. A number of studies attempt to quantify the damages from $\mathrm{CO}_{2}$ emissions, due to future global climate change (see the exhaustive list of studies in Tol 2007). Most

\footnotetext{
${ }^{24}$ Given the much smaller area within the Mexico City basin, a given amount of auto emissions becomes more concentrated in the air than in Los Angeles. Some further adjustment would be required if total pollution damages are convex in ambient concentrations (i.e., marginal damages are an increasing function of concentrations). However, available evidence suggests that aggregate mortality risks among a given population are roughly linear in ambient concentrations (e.g., Burtraw et al. 1998)

25 The estimate is broadly similar to that in World Bank (2002b). This study finds a benefit of $\$ 760$ million (1999 USD) associated with a 10 percent reduction in particulate and ozone levels in Mexico City in 2010. If this could be achieved by reducing gasoline consumption by 31 percent, or 760/0.9 million gallons, the value per gallon reduced would be 90 cents.
}

\footnotetext{
${ }^{26}$ Mayeres and Proost (2001) assume that per gallon pollution costs are larger for diesel than gasoline (though this depends strongly on local pollution control policies). Our results are only moderately affected by different assumptions about diesel fuel damages.
} 
estimates are somewhere between about $\$ 5$ and $\$ 20$ per ton of $\mathrm{CO}_{2}$, though there is little consistency among the estimates (in some studies catastrophic risks are the dominant damage, while in others it is either market impacts like agricultural damage, or non-market impacts like human health from the spread of tropical disease). Nordhaus and Boyer (2000) provide the most comprehensive estimate and their central value (after updating in Nordhaus 2007) is $\$ 8$ per ton. Stern (2007) obtains a central damage estimate of $\$ 85$ per ton of $\mathrm{CO}_{2}$, as he uses a much lower discount rate- specifically zero discounting of future utility — than the market discount rate assumed in Nordhaus (2007). While the choice of discount rate is highly contentious, we ourselves are somewhat uncomfortable with zero discounting of future utility as it has all sorts of perverse implications; for example, it implies that every previous generation should have been made worse off to make the current generation better off. Weitzman (2008) takes a different perspective on catastrophic damages than in other studies. He shows that, under a plausible utility function, marginal damages from $\mathrm{CO}_{2}$ emissions can become infinitely large if there is a small, but positive, probability, of truly catastrophic climate change that could permanently reduce world consumption by 99 percent. Clearly, the appropriate value to place on $\mathrm{CO}_{2}$ is much disputed. We adopt a benchmark value of $\$ 10$ per ton, and illustrate the implications of other assumptions in the sensitivity analysis.

A gallon of gasoline and a gallon of diesel contain 0.0024 and 0.0028 tons of carbon respectively (http://bioenergy.ornl.gov/papers/misc/energy conv.html). Combustion of these two fuels produces about 0.009 and 0.0011 tons of $\mathrm{CO}_{2}$ respectively. Thus, our benchmark damage assumption amounts to about 9 and 11 cents per gallon of gasoline and diesel. Again, pollution costs for diesel are converted to costs per passenger mile by public bus.

Congestion costs. We are not aware of a direct estimate of the marginal cost of traffic congestion for Mexico City (averaged across different routes and time of day). In fact, there are not that many estimates, even for major urban areas in the United States. We therefore adopt the following procedure.

We assume a free flow auto speed of $30 \mathrm{mph}$, so the time per mile if roads were uncongested, $\alpha$ in equation (15), would be 0.033 hours per mile. The actual time to drive an auto mile in Mexico City, the inverse of the current auto speed $(14.3 \mathrm{mph})$ is 0.070 hours per mile (IAPT 2007), implying a delay per mile of 0.037. Plugging these values into (15), with $\tilde{M}=M^{0}$, gives $\gamma=1.121$.

The gross hourly wage rate for Mexico City is taken to be $\$ 4.0$ (IMF 2007). Following US studies (see the review in Small and Verhoef 2007), we assume the value of travel time is half the hourly wage. This gives a monetized marginal congestion cost of 27.1 cents per vehicle mile, or 18.5 cents per passenger mile. 
Passenger car equivalents. We assume the same value for the passenger car equivalent for an extra vehicle mile by public bus as used by Parry and Small (2008) for London, namely 5. And for microbuses we assume the passenger car equivalent for an extra vehicle mile is 3. Diving by vehicle occupancy gives the passenger car equivalents in passenger miles.

Marginal accident cost. Parry and Small (2005) put the marginal external costs of traffic accidents at 3.0 cents per vehicle mile, averaged across driving in the United States. This mainly reflects the costs of fatal and non-fatal injury risks (that are not internalized by drivers), property damage to vehicles, and medical costs. We make two adjustments to this US estimate. First, we divide by four to account for the lower value of injuries and property values in Mexico City with its lower per-capita income. Second, to make some allowance for differences in crash rates and vehicle safety, we multiply by the ratio of fatalities per vehicle mile in Mexico City relative to that in the United States, where this ratio is $(38 / 15) .{ }^{27}$ This gives 1.9 cents per vehicle mile or 1.2 cents per passenger mile.

For microbus and public bus, accidents costs per vehicle mile are taken to be the same as for auto. Buses have much greater weight and therefore are far more lethal to other road users in a collision for a given vehicle speed. However, offsetting this is that they drive more slowly (thereby reducing the severity of any given accident) and they are driven by professionals. For comparison, a study by FHWA (1997) put marginal external accident costs per vehicle mile for single and combination trucks at roughly the same as those for autos.

Fuel price elasticities. There is a large empirical literature on gasoline price elasticities for advanced industrial countries, especially the United States. Surveys by Goodwin et al. (2004) and Glaister and Graham (2002) put the long run elasticity at around -0.6 to -0.7 , while assessments by US DOE (1996) and Small and Van Dender suggest an elasticity of around -0.4. Typically, around a half to two-thirds of the elasticity comes from long-run improvements in vehicle fuel economy, and the remainder from reduced vehicle use. We are aware of only one study that uses Mexican data. Eskeland and Feyzioglu (1994) put the gasoline demand elasticity at -0.8 , using panel data from 31 Mexican states. We might expect a somewhat larger mileage/fuel price response for Mexico City, given the wider availability of transit alternatives to private car use. We adopt a benchmark value of -0.6 for the gasoline price elasticity, with the assumed response split equally between better fuel economy and reduced mileage. For the

\footnotetext{
${ }^{27}$ Statistics are from IAPT (2007) and BTS (2004), Table 2.17, and are expressed in deaths per billion vehicle miles of travel.
} 
benchmark case, we assume that mileage/fuel price and fuel economy/fuel price elasticities are the same for autos and microbuses.

There is a potential problem with applying evidence based on nationwide fuel demand responses to a fuel tax increase that is specific to one region (see also the discussion in Section 5). If fuel taxes are increased substantially in Mexico City, but not in neighboring regions, people might be induced to drive to lower price regions for refueling (or for smuggling gasoline into Mexico City). We do not have evidence on how this effect might increase the overall magnitude of the region-specific fuel price elasticity. This is another reason for being cautious about the welfare effects from the large fuel price increases considered above.

Public bus and rail mileage elasticities. Again, there is a substantial body of empirical work on the behavioral response of passenger travel by public bus and rail to higher fares, though it mostly applies to the United States. However, we see no obvious reason why these estimates would over or understate behavioral responses for Mexico City. Therefore, based on Lago et al. (1981), Goodwin (1992), and Pratt et al. (2000), we assume that the own-fare demand elasticity is -0.5 for bus and -0.3 for rail.

Relative price coefficients. Suppose, for the moment, that there were no microbuses and only autos used gasoline. Then the reduction in auto mileage per gallon reduction in gasoline, would simply equal auto fuel economy (miles per gallon), times the fraction of the reduction in gasoline use that comes from reduced miles, as opposed to improved fuel economy, which is 0.5 (Parry and Small 2005). With some gasoline used for microbuses, we scale this back by the fraction of gasoline used for autos $(0.88)$, to obtain $\rho_{A G}=.44$ times auto fuel economy. Conversely, $\rho_{M B G}=0.06(=0.5 \times 0.12)$ times microbus fuel economy.

Assumptions about how passengers re-allocated among other modes in response to higher prices for one mode are described in the main text.

Initial transit fares and operating costs. Currently, the subway carries 4.4 million trips every day and the fare per subway trip is 20 cents (from http://wikitravel.org/en/Mexico_City, accessed February 2008). According to the World Bank (2002a), Table 8.3, the fare in 2000 was 15 cents. For 2005, we assume the fare was 18 cents, and passenger trips were 4.2 million, hence assumed annual revenue is $\$ 321$ million. Dividing by total passenger miles by rail, 427 per capita times the population of 18 million, gives a fare per passenger mile of 4 cents. We assume the revenue to operating cost revenue for rail in 2005 was the same as in 2000, which was 53 percent (World Bank 2002a, Table 8.3). Therefore, average operating 
costs per passenger mile are 7.5 cents or, multiplying by passenger occupancy, $\$ 13$ per vehicle mile. For the Washington and Los Angeles rail systems, Parry and Small (2008) put the average operating cost per vehicle mile at around $\$ 50$. Roughly speaking these figures seem consistent, given that wages (the main component of operating costs) are four times greater on average in the United States. Following Parry and Small (2008) we assume that 10 percent of average operating costs for rail reflect fixed costs; therefore, the marginal operating cost is 6.8 cents per passenger mile, or $\$ 11.7$ per vehicle mile.

For microbus, fares are approximately 1 peso per km for trips less than $3 \mathrm{~km}$ and .3 pesos per $\mathrm{km}$ for longer trips (http://wikitravel.org/en/Mexico_City). We assume the initial fare is 0.7 pesos per km, or 6 cents per mile.

We were unable to find direct estimates of fare revenues and operating costs from the bus public company for Mexico City and we therefore extrapolate these values. We assume the fare per mile for public bus and microbus are the same. As for average operating costs per vehicle mile, Parry and Small (2008) compute them for bus to be about one-quarter of those for rail. Applying the same ratio, operating costs for bus would be $\$ 3.25$ per vehicle mile for Mexico City, or 10.5 cents per passenger mile. 